University of Rhode Island

DigitalCommons@URI

Open Access Master's Theses

2016

Thalassiosira Community Composition and Diversity in

Narragansett Bay

\title{
Sarah Flickinger
}

University of Rhode Island, sarahflickinger@my.uri.edu

Follow this and additional works at: https://digitalcommons.uri.edu/theses

\section{Recommended Citation}

Flickinger, Sarah, "Thalassiosira Community Composition and Diversity in Narragansett Bay" (2016). Open Access Master's Theses. Paper 880.

https://digitalcommons.uri.edu/theses/880

This Thesis is brought to you for free and open access by DigitalCommons@URI. It has been accepted for inclusion in Open Access Master's Theses by an authorized administrator of DigitalCommons@URI. For more information, please contact digitalcommons-group@uri.edu. 
THALASSIOSIRA COMMUNITY COMPOSITION AND DIVERSITY IN

NARRAGANSETT BAY

BY

SARAH FLICKINGER

A THESIS SUBMITTED IN PARTIAL FULFILLMENT OF THE REQUIREMENTS FOR THE DEGREE OF

MASTER OF SCIENCE

IN

OCEANOGRAPHY

UNIVERSITY OF RHODE ISLAND

2016 


\section{MASTER OF SCIENCE THESIS}

$\mathrm{OF}$

\section{SARAH FLICKINGER}

APPROVED:

Thesis Committee:

Major Professor Tatiana Rynearson

Candace Oviatt

Bethany Jenkins

Nasser H. Zawia

DEAN OF THE GRADUATE SCHOOL 


\begin{abstract}
Diatoms contribute $40-45 \%$ of marine primary production. Understanding the contributions of individual species to diatom communities is important in light of warming ocean waters and changing food webs. Here, the diatom genus Thalassiosira, which exhibits irregular pulses in abundance in Narragansett Bay, is examined using data from the Narragansett Bay Long Term Phytoplankton Time Series. High-throughput sequencing (HTS) at the highly-variable V4 region of the $18 \mathrm{~S}$ ribosomal gene identified fourteen Thalassiosira taxa in monthly samples over a sixyear time period (December 2008-December 2014), seven of which had not previously been identified in this time series. During the same time period, only four Thalassiosira taxa were identified through light microscopy (LM) counts. Many of the newly identified species for this location are small in diameter and difficult to identify using LM. However, they appear to be very frequent and may have a significant ecological role. $18 \mathrm{~S}$ gene copy number was shown to greatly effect sequence abundance for this locus and this genus, and therefore only presence data was analyzed. Thalassiosira species grouped into four seasonal assemblages, although only $25 \%$ of this pattern was explained by temperature, suggesting that other factors such as competition or prey selection may drive Thalassiosira community structure. Comparisons to historical records show possible shifts in frequency and abundance of Thalassiosira species.
\end{abstract}




\section{ACKNOWLEDGEMENTS}

This thesis would not have been completed without the support, guidance and friendship of many individuals. I must first thank my advisor, Tatiana Rynearson, for her patience and encouragement throughout this process and for her insight which greatly improved this work. She has enabled me to develop a thorough understanding of this subject and helped me to grow as a scientist and thinker. It has been an honor to work under her guidance alongside many great lab mates. I learned so much from all of you. I am particularly grateful to lab manager extraordinaire, Amanda Montalbano, for assisting with all things, large and small.

I am thankful for the support and advice of a wonderful thesis committee of Dr. Candace Oviatt and Dr. Bethany Jenkins and to Dr. Chris Lane, my thesis committee chair. Mentors Dave Ely, Janet Schwarz, and Dr. John McGeary were instrumental in shaping my interest in biology and genetics. I am very appreciative to all former and present Narragansett Bay Phytoplankton Assistants who collected the data used in this thesis. Dr. Malcolm McFarland, Dr. Jan Rines, and Samantha Decuollo: thank you for sharing your knowledge about phytoplankton identification.

I am so grateful for the funding sources that supported me and this work, including support from the University of Rhode Island for the Narragansett Bay LongTerm Phytoplankton Monitoring Program, the Robert '35 and Marjorie '36 Fillmore Memorial Endowment, the Ann Durbin Memorial Fund, the RI Science and Technology Council and Rhode Island EPSCoR (NSF Cooperative Agreement \#EPS1004057) which made possible the use of the RI Genomics and Sequencing Center, the Marine Life Science Center and the Brown University Center for Computation and 
Visualization. Thank you to the URI Office of Marine Programs and particularly to Sara Hickox, Katie Pratt, Frank Baker and Josh Wood. It was an honor to work with you all.

Finally, friends and family were an incredible source of support, encouragement, and love throughout the past three years, for which I am so greatly indebted. John Flickinger inspired me with his love of the outdoors and his unlimited integrity. I am so thankful for his encouragement and guidance. 


\section{TABLE OF CONTENTS}

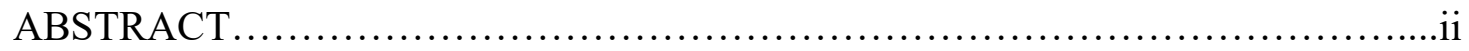

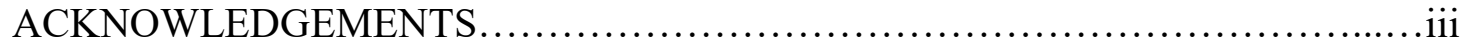

TABLE OF CONTENTS ........................................................v

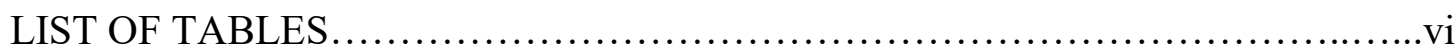

LIST OF FIGURES ........................................................vii

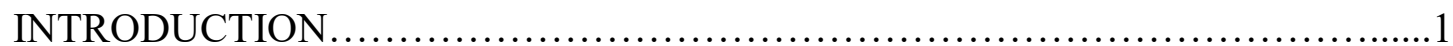

METHODS..............................................................

RESULTS.................................................................. 15

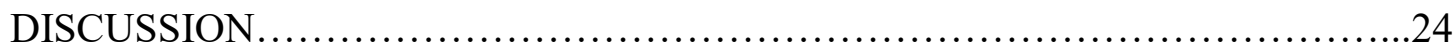

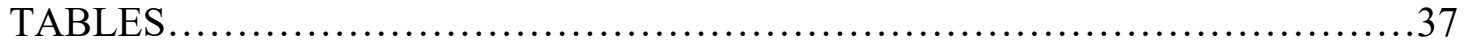

FIGURES ................................................................. 44

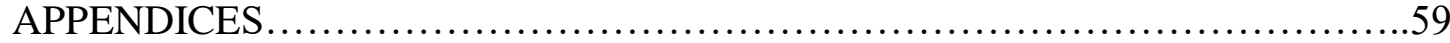

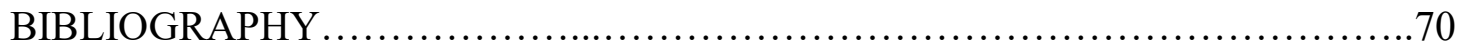




\section{LIST OF TABLES}

TABLE

PAGE

Table 1. Diatom Barcode Genes........................................................ 37

Table 2. Reference 18s V4 Database........................................... 38

Table 3. Mock Community Species.............................................40

Table 4. Thalassiosira Species in Narragansett Bay.............................. 41

Table 5. Thalassiosira Cell Diameters and Ranges................................42

Table 6: BEST Environmental Correlations......................................43 


\section{LIST OF FIGURES}

FIGURE

PAGE

Figure 1. Map of Sampling Station .................................................4

Figure 2. Thalassiosira Abundance in Narragansett Bay.............................45

Figure 3. Rarefaction Curves 18S................................................ 46

Figure 4. V4 Maximum Likelihood Tree..........................................47

Figure 5. Whole 18S Maximum Likelihood Tree.....................................48

Figure 6. Mock Community Sequence \% Composition..............................49

Figure 7. Field Sample Thalassiosira Presence/Absence............................50

Figure 8. Thalassiosira Species Frequency $2008-2014 \ldots \ldots \ldots \ldots \ldots \ldots \ldots \ldots \ldots \ldots \ldots \ldots . . . . . \ldots 1$

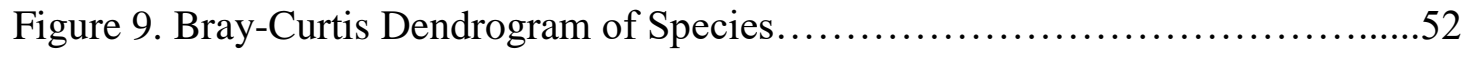

Figure 10. MDS Plot of Monthly Species Compositions............................53

Figure 11. Bray-Curtis Dendrogram of Samples.................................54

Figure 12. Occurrence Frequency of 8 Most Frequent Taxa........................55

Figure 13. Temperature and Salinity Ranges.....................................56

Figure 14. Principal Components Analysis of Environmental Factors.................57

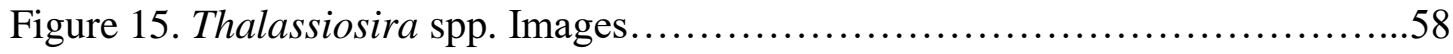




\section{INTRODUCTION}

Abbreviations used in this thesis in order of occurrence:

HTS: High Throughput Sequencing

LM: Light Microscopy

ITS2: Internal Transcribed Spacer 2

NCBI: National Center for Biotechnology Information

ML: Maximum Likelihood

BIC: Bayesian Information Criterion

PCR: Polymerase Chain Reaction

MC: Mock Community

MED: Minimum Entropy Decomposition

OTU: Operational Taxonomic Unit

DIN: Dissolved Inorganic Nitrogen

DIP: Dissolved Inorganic Phosphorus

Si: Silicate

PCA: Principal Components Analysis

SSU: Small Subunit

Phytoplankton account for over $45 \%$ of global primary production despite comprising only $1 \%$ of photosynthetic biomass (Field et al. 1998), underscoring the importance of these organisms. Within the phytoplankton, diatoms account for roughly 50\% of oceanic primary production (Rousseaux and Gregg 2014). Diatoms are unicellular, photosynthetic eukaryotes characterized by a siliceous frustule. There are an estimated 30,000 to 200,000 extant diatom species (Mann and Droop 1996, Mann and Vanormelingen 2013), indicating the great diversity within this class of phytoplankton. In coastal systems, diatoms play a crucial role in the silica cycle and in carbon flux (Treguer and De La Rocha 2013). Understanding the ecology of individual diatom species is essential for generating estimates of phytoplankton community composition, production, export and phenology. Diatom species traditionally are differentiated based on morphology (reviewed in Mann 1999), although a lineage- 
based species approach has gained support recently (reviewed in Alverson 2008), in which molecular and morphological characteristics are used to differentiate phylogenies. Here, we examine the diatom genus Thalassiosira, a common genus consisting of dozens of species that are often seen coexisting, using data from the Narragansett Bay Long Term Phytoplankton Time Series.

The Narragansett Bay Long-Term Time Series was initiated by D. Pratt and T. Smayda (Pratt 1965, Smayda 1998) in 1959 and weekly sampling has been conducted by graduate students since 1999 . Narragansett Bay is a highly productive 234 square kilometer estuary (Nixon et al. 2009) characterized by a phytoplankton community dominated by diatoms (Pratt 1965, Karentz and Smayda 1984, Oviatt et al. 2002). Understanding the ecology and community dynamics of this estuary are important due to the role of diatoms in affecting water quality, biogeochemical cycling, and production (Legendre 1990, Treguer and De La Rocha 2013). Time series samples are collected from a station in the southern west passage of Narragansett Bay, which experiences seasonal cycling of physical, chemical and biological signals, including temperature, nutrients, and plankton abundances and diversity (Pilson 1985, Nixon et al. 2009). Since 1959, nutrient inputs to Narragansett Bay have changed and the average winter temperature has increased by $2.2^{\circ} \mathrm{C}$ from 1960-2007 (Nixon et al. 2009, Smith et al. 2010). The scale, timing and even the occurrence of the spring bloom have also been in flux (Oviatt et al. 2002). Both bulk diatom counts and chlorophyll $a$ concentrations have declined (Smayda 1998, Li and Smayda 1998), and the chlorophyll $a$ decline is correlated with warmer water temperatures (Oviatt et al. 2002). 
The dynamics and changes of some diatom genera in Narragansett Bay have been studied. The genus Skeletonema has been a significant focus of study since it historically composed $48-50 \%$ of the phytoplankton community in Narragansett Bay (1959-1979), and more recently composed 33\% of the phytoplankton community in Narragansett Bay (1980-1997) (Borkman and Smayda 2009). Overall Skeletonema abundance in Narragansett Bay has decreased by almost half in the period from 19591997 and variations in abundance correlate strongly with environmental factors, including temperature and irradiance (Borkman and Smayda 2009). Recent high throughput 28S sequencing of cryptic Skeletonema species in Narragansett Bay discovered unknown diversity and seasonal patterns (Rynearson and Canesi, in press). From 1959 through 1980, some Thalassiosira species were identified as important contributors to the Narragansett Bay phytoplankton community. In particular, $T$. nordenskioeldii was identified as the $5^{\text {th }}$ most abundant phytoplankton species and was an important winter phytoplankton species, with a 5 year abundance fluctuation cycle (Karentz and Smayda 1984). Investigating potential changes in abundance or timing in Thalassiosira species is valuable given that diatom genera with larger cell sizes may contribute more significantly to carbon fixation than smaller cells such as Skeletonema, due to the positive relationship between carbon content and cell volume in diatoms (Strathmann 1967, Menden-Deuer and Lessard 2000). Therefore, it is important to determine whether Thalassiosira species timing or frequencies have changed.

Thalassiosira is a centric diatom genus that can be chain forming and is very common in Narragansett Bay. At least 11 species within this genus have been 
observed in Narragansett Bay since the initiation of the Long Term Time Series in 1959, including T. eccentrica, T. rotula, T. gravida, T. pseudonana, T. punctigera, $T$. pacifica, T. anguste-lineata, T. nordenskioeldii, T. kushirensis, T. decipiens and T. hyalina as well as unidentified Thalassiosira spp. Cells from this genus can be very abundant in Narragansett Bay, reaching cell numbers of $>1.6$ million cells/L.

Not only is Thalassiosira an important diatom genus in Narragansett Bay but various Thalassiosira species are also an important component of phytoplankton communities across the globe, including estuarine, coastal and open ocean regions [e.g. Narragansett Bay (Pratt 1965, Smayda 1998), the Argentinean coast (Popovich and Gayoso 1999), a Scottish sea-loch (Harris et al. 1995), the North Sea (Hoppenrath et al. 2007), German and Dutch estuaries (Muylaert and Sabbe 1996), the subarctic Pacific (Yoshie et al. 2010)]. Thalassiosira species have been abundant for at least the past century in British Columbia estuaries (McQuoid and Hobson, 1997). With respect to the changing climate, understanding the diversity, community composition of Thalassiosira and factors that drive these patterns is increasingly important.

Environmental factors are principal drivers of diatom ecology and specifically, Thalassiosira ecology. Many Thalassiosira species exhibit temperature, nutrient, and light sensitivity, and therefore occur cyclically in conjunction with nutrient cycles and seasons. In lab studies, Thalassiosira weissflogii stopped cell division in low silicon concentrations (De la Rocha et al. 2010). In contrast, the species continues dividing but produces cells with low N, P and Si compositions when nitrogen limited (De la Rocha et al. 2010). There are also observed differences in responses to nutrient stress between Thalassiosira species; T. oceanica maintains chlorophyll $a$ levels when 
grown at lower Fe concentrations whereas T. weissflogii demonstrates a $60 \%$ decrease in chlorophyll $a$ when grown at low Fe (Sunda and Huntsman 1995). Some of these physiological differences between the species have been observed in the field as well. Chappell et al. (2013) found that Thalassiosira community composition in the Northeast Pacific was correlated with temperature and iron concentrations.

Despite compelling evidence that this genus deserves further study, there are a few challenges with studying the Thalassiosira genus, primarily that identification of Thalassiosira species is known to be difficult, especially using light microscopy (LM) due to subtle differences in frustule morphology (Kaczmarska et al. 2009). Some Thalassiosira species are unidentifiable with LM methods (Hasle 1978). Complicating matters, the morphology of Thalassiosira species can vary, especially in the variable environmental conditions of estuaries, making LM identification all the more difficult (Hevia-Orube et al. 2015). Thalassiosira identification can be done using scanning electron microscopy (Hoppenrath et al. 2007), but this requires time and expertise. Recently, molecular barcoding has been used to identify Thalassiosira species as well as other diatom species (e.g. Hamsher et al. 2011, Moniz and Kaczmarska 2010, Zimmerman et al. 2011, Luddington et al. 2012, Hamsher et al. 2013). This new approach has allowed for the discovery of previously unrecorded local species in North Sea estuaries (Hoppenrath et al. 2007). Hamsher et al. (2013) compared morphological and molecular sampling to estimated Thalassiosira species richness in the Bay of Fundy and found additional rare and difficult to identify Thalassiosira species using molecular methods over morphological methods. Furthermore, small volume sampling methods, such as the $1 \mathrm{~mL}$ sample counted weekly for the 
Narragansett Bay Long-Term Phytoplankton Time Series, can underestimate species counts by $20-45 \%$ (Rodriguez-Ramos et al. 2013). Species richness may be more accurately obtained through molecular methods, such as high-throughput sequencing.

This study will use a high throughput sequencing community genetics approach to investigate Thalassiosira dynamics in Narragansett Bay and will address the following questions: 1) What Thalassiosira species are present in Narragansett Bay? 2) Are there annual and or seasonal patterns of Thalassiosira species composition in the Narragansett Bay? 3) Do fluctuating environmental conditions drive these putative patterns of species composition? To gain a more thorough understanding of Thalassiosira diversity and seasonal patterns in Narragansett Bay, we sequenced the $18 \mathrm{~S}$ V4 locus for 80 field samples taken over the course of six years. With this approach, Thalassiosira species not previously identified in Narragansett Bay were identified and correlated with environmental conditions. 


\section{METHODS}

\section{Field Sampling Methods}

As part of the Narragansett Bay Long-Term Phytoplankton Time Series, weekly water samples were collected from Station II in the southern west passage of Narragansett Bay, at $41.57^{\circ} \mathrm{N}$ and $71.39^{\circ} \mathrm{W}$ (Figure 1). Surface water samples were collected and filtered through $0.22 \mu \mathrm{m}$ pore size, $25 \mu \mathrm{m}$ diameter Millipore ExpressPlus filters. The volume filtered was dependent on the Secchi depth measured for the sampled water; $100 \mathrm{~mL}$ of water were filtered per each meter of Secchi depth. Three replicate filters were collected each week and stored at $-80^{\circ} \mathrm{C}$ for later DNA extraction and analysis.

\section{Molecular Barcoding}

Potential DNA barcodes were selected from current literature, including the variable V4 region of the $18 \mathrm{~S}$ ribosomal DNA coding gene, the V9 region of the $18 \mathrm{~S}$, and the internal transcribed spacer 2 (ITS2) ribosomal gene (Table 1) (Chappell et al. 2013, Gast et al. 2004, Hamsher et al. 2011, Hamsher et al. 2013, Luddington et al. 2012, Moniz and Kaczmarska 2010, White et al. 1990, Zimmerman et al. 2011). Candidate loci were assessed using DNA sequences for Thalassiosira species available from the National Center for Biotechnology Information (NCBI) GenBank database. Potential barcodes were evaluated based on the number of identifiable Thalassiosira species available in the NCBI database (more species were preferable), its ability to distinguish among species (higher inter-specific variation was preferable) and the suitability of the locus for Illumina MiSeq Sequencing (amplicon length < 
500bp). Two $18 \mathrm{~S}$ regions (V4, V9) had the highest number of Thalassiosira sequences available in GenBank. Sequences for 30 Thalassiosira species were available in GenBank for 18S V9 region amplified by primers in Gast et al. (2004), but 18 of these species were indistinguishable at this locus. At the V4 region, 31 Thalassiosira species were available in GenBank and at least 17 of them could be distinguished from one another. Primers to amplify this region (Zimmerman et al. 2011) were selected for this study (forward primer ATTCCAGCTCCAATAGCG and reverse primer GACTACGATGGTATCTAATC). These primers were used successfully by Luddington et al. (2012) to differentiate 30 Thalassiosira species. Primers were assessed in silico with sequences representing all taxa that might be found in the Narragansett Bay phytoplankton community and found to amplify diatoms and raphidophytes only. The primers were not expected to amplify dinoflagellates.

To assess the power of the 18S V4 locus in resolving Thalassiosira species, genetic trees were constructed using the maximum likelihood (ML) method. Forty-five 18S V4 Thalassiosira sequences representing 20 Thalassiosira species from GenBank were compiled with two outgroup species (Skeletonema marinoi and Skeletonema menzelii) to create a curated reference database (Table 2). This curated database included taxonomically verified sequences only. Sequences representing a 420 bp V4 amplicon from Zimmerman et al. (2011) were aligned using Clustal.w (Larkin et al. 2007). The HKY+G model (Hasegawa et al. 1985) was selected to be the best fit nucleotide substitution model based on Bayesian Information Criterion (BIC) using jModelTest2 (Darriba et al. 2012, Guindon and Gascuel 2003). This model allows for variable nucleotide base frequencies and has one transition rate and one transversion 
rate. The best ML tree was created with Paup* version 4.0b10 (Swofford 2003) and its reliability was tested using 100 bootstrap replicates. An ML tree was also constructed using the same methods for a $1552 \mathrm{bp}$ partial $18 \mathrm{~S}$ gene with the same sequence accession numbers as the reference database. The best fit nucleotide substitution model chosen with BIC for this locus was the TIM1+I+G model, which has a variable nucleotide base frequency, variable transition rates and two transversion rates.

\section{Mock Community Design}

To test and validate the community high throughput sequencing approach used for this study, four mock communities were constructed to provide insight into the effects of $18 \mathrm{~S}$ gene copy number variation, the amount of polymerase chain reaction (PCR) bias, and the amount of sequencing bias inherent to this method. The mock communities were comprised of varying amounts of four Thalassiosira species, three other diatom species, a dinoflagellate and a raphidophyte (Table 3). To obtain mock communities, monocultures of different species were maintained in exponential growth in F/2 media. Concentrations were assessed by counting $1 \mathrm{~mL}$ samples of each strain using a Sedgwick-Rafter counting chamber (Graticules S52) under 100-200x magnification, depending on species cell size. Cell concentrations were used to calculate the volume of each culture need to achieve the target species proportions. The calculated volumes of each strain were filtered simultaneously on $0.2 \mu \mathrm{m}$ pore size, $25 \mu \mathrm{m}$ diameter Millipore ExpressPlus filters and stored at $-20^{\circ} \mathrm{C}$ for up to 1 month, until DNA extraction.

\section{DNA Extraction and Amplification Protocols}


Previously extracted DNA from 68 monthly surface water samples from the Narragansett Bay Long-Term Phytoplankton Time Series were selected from the period of December 2008 to December 2014 (Canesi and Rynearson, in press) providing samples containing a range of Thalassiosira concentrations, from zero detected cells to $1,683,000$ cells/L. An additional twelve monthly samples from January 2014-December 2014 were selected based on maximum Thalassiosira cell abundance, for a total of 24 semi-monthly samples from 2014 and 80 field sampling dates overall (Appendix 1). Genomic DNA from the additional 2014 samples and the mock community samples was extracted from frozen filters using the DNeasy Blood and Tissue Kit (Qiagen, Valencia, CA) with the addition of approximately 15 triplepure high impact $0.5 \mathrm{~mm}$ zirconium beads (KSE Scientific) during the lysis step prior to vortexing and incubating. Genomic DNA from each of the four mock communities was extracted in triplicate.

A $420 \mathrm{bp}$ fragment within the variable V4 region of the $18 \mathrm{~S}$ rDNA gene was amplified using the primers described by Zimmerman et al. (2011) modified by the addition of Illumina specific adaptors: D512_illumina: 5' TCGTCGGCAGCGTCAGATGT GTATAAGAGACAGATTCCAGCTCCAATAGCG 3' and D978_illumina: 5' GTCTCGTGGGC

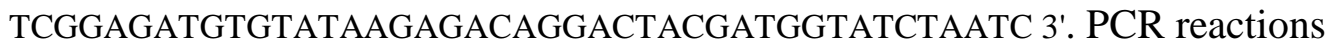
contained the following reagents: $1 \mathrm{x}$ Bio-x-Act Short Mix (Bioline USA Inc.), $0.5 \mu \mathrm{M}$ each forward and reverse primer and approximately 0.3-2.7 ng DNA template. Reactions were amplified using a multi-step thermocycler protocol, which consisted of a two minute denaturing step at $94^{\circ} \mathrm{C}$, followed by 20 cycles of 30 seconds at $94^{\circ} \mathrm{C}, 30$ seconds at $49^{\circ} \mathrm{C}$ and 30 seconds at $72^{\circ} \mathrm{C}$ followed by 15 cycles of 30 seconds at $94^{\circ} \mathrm{C}$, 
30 seconds at $67^{\circ} \mathrm{C}$ and 30 seconds at $72^{\circ} \mathrm{C}$, followed by 10 minutes at $72^{\circ} \mathrm{C}$.

Technical variation of this PCR reaction was measured through triplicate amplification of one randomly selected field sample (12/30/2014) and one mock community sample (MC1), using identical template DNA concentrations for the triplicate PCR reactions. PCR amplicons were cleaned with Ampure XP beads (Beckman Coulter, Inc.), quantified with the Qubit High Sensitivity DNA Assay Kit (Thermo Fisher Scientific, Inc.), amplified for an additional five cycles to add Nextera indices and adaptors (Illumina, Inc.) and cleaned again with Ampure XP beads.

\section{Sequencing and Sequence Processing}

PCR products were pooled with the KAPA qPCR kit (Kapa Biosystems) and sequenced on the Illumina MiSeq platform with V2 chemistry (2x250bp reads; Illumina, Inc.) at the University of Rhode Island Genomics and Sequencing Center. The resulting paired end sequencing reads were first trimmed to remove low quality bases and Illumina adaptors using Trimmomatic PE (Bolger et al., 2014) using a 4 base pair sliding window quality score of 20 and a minimum read length of 200 basepairs. Paired end sequences were merged using the BBmerge function from BBMap (Bushnell, Sourceforge.net/projects/bbmap/) using the default settings. Trimmed and merged sequences were first filtered to a minimum length of 380 basepairs and a maximum expected error (based on phred quality scores) of 1 and then concatenated and dereplicated in USEARCH (Edgar 2010). The resulting sequences formed the final dataset for the community genetic analysis.

To identify taxa in the samples, filtered sequences were decomposed into minimum entropy decomposition (MED) nodes (Eren et al. 2015) using the default 
settings. Chimeric sequence nodes were identified and removed from results using the UCHIME denovo program (Edgar 2011) with all default settings. Taxonomy was assigned to remaining MED nodes using the blast method within the assign_taxonomy.py script from QIIME (Caporaso et al. 2010) and a reference database of Thalassiosira sequences curated from GenBank (Table 2). MED nodes are equivalent to operational taxonomic units (OTUs), which were used here to assign sequences to one species or to a group of species for cases in which a sequence was indistinguishable between two species. UCHIME denovo was run separately with only mock community samples and then separately with only field samples as expected chimeric sequences are higher for a lower diversity community, as in the mock communities. Nodes that contained fewer than $0.04 \%$ of total sequence reads for that sample were removed as possible sequencing error (Quail et al. 2012).

\section{Statistical and Environmental Analyses}

Thalassiosira species presence-absence data were obtained from the taxonomy assigned to MED nodes per the $0.04 \%$ cutoff noted above and used to assess species composition of the water samples and mock communities. Variation within triplicate extraction and triplicate PCR reactions was assessed using ANOVA. Observed mock community compositions were compared with the expected compositions through $\chi$ square goodness-of-fit-tests.

Bray-Curtis similarity was computed between all field samples and between all species identified in the field samples in PRIMER v6.1.6 (PRIMER-E Ltd.). To examine temporal variation of species composition on yearly and monthly time scales, likelihood of species occurrence was calculated by summing species data by year or 
month, respectively, and normalizing by sampling effort. Bray-Curtis similarity was then calculated for the likelihood of both yearly and monthly species presence. Cluster dendrograms and multidimensional scaling plots (MDS) based on Bray-Curtis similarity were created in PRIMER v6.1.6 (PRIMER-E Ltd.).

Correlations of community composition with environmental conditions were analyzed using environmental data obtained from the Narragansett Bay Long-Term Phytoplankton Time Series (http://www.gso.uri.edu/phytoplankton; surface temperature, surface salinity, chlorophyll $a$, dissolved inorganic nitrogen [DIN], dissolved inorganic phosphorus [DIP], and silicate [Si]). For a small subset of field samples (seven dates) for which chlorophyll $a$ data was not available from the time series, chl $a$ data were obtained from the Marine Ecosystems Research Laboratory (http://www.gso.uri.edu/merl/data.html) Tank 98 bay sample dataset, which is collected weekly from the University of Rhode Island Graduate School of Oceanography dock $\left(41.49^{\circ},-71.42^{\circ}\right)$. This sample site is located approximately 9.2 kilometers south of Station II in the west passage of Narragansett Bay and thus shares a very similar physical environment with Station II.

Additionally, temperature and salinity data for 9/15/2014 and nutrient data for 10/5/2014 were obtained from the MERL dataset. Photosynthetically active radiation (PAR) data were obtained from the Narragansett Bay National Estuarine Research Reserve's System Wide Monitoring Program (41.64ำ $\left.-71.34^{\circ}\right)$. PAR data were downloaded from the National Estuarine Research Reserve's Centralized Data Management Office (http://cdmo.baruch.sc.edu/). Variation in environmental data (surface temperature, surface salinity, DIN, DIP, Si, chl $a, \mathrm{PAR}$ ) was analyzed with a 
Principal Components Analysis (PCA) also in PRIMER v6.1.6 based on Euclidean distance. Values for salinity, chlorophyll $a$, DIN, DIP, and Si were log transformed prior to PCA construction. A multivariate trend correlation (BIOENV) analysis was used to correlate environmental factors with the community composition also in PRIMER v6.1.6.

\section{Cell Imaging}

Thalassiosira cells from one Naphrax preserved sample from the Long-Term Time Series were imaged using a Nikon E800 microscope at 200x to verify presence of species identified in the HTS results. The chosen sample data was January 11, 2011. 


\section{RESULTS}

Thalassiosira in the Narragansett Bay Long-Term Phytoplankton Time Series, December 2008 to December 2014

Based on microscopy records in the long-term dataset, Thalassiosira species were present in $85 \%$ of the weekly cell counts of Station II surface water collected between December 2008 and December 2014 (Figure 2). The cell abundance of the genus ranged from zero observed cells to $1,683,000$ cells/liter, with a median abundance of 14,000 cells/liter (Appendix 1). During the same time period, four Thalassiosira species or groups of species were recorded in the long-term data set. Two were identified to the species level (T. nordenskioeldii, T. punctigera) and two represented multiple species ( $T$. rotula/T. gravida and Thalassiosira spp.). The last two categories represent species that are difficult to distinguish at the resolution of light microscopy.

Thalassiosira varied in occurrence and abundance (Appendix 2). T. punctigera was the least abundant and the least common taxa; it was present in $9.3 \%$ of samples during the time period with a maximum abundance of 51,000 cells/liter. It appeared in the months of September through January and was only recorded in three of the six years. T. nordenskioeldii was present in $14.2 \%$ of samples from this period and reached a maximum abundance of 1,575,000 cells/liter. It occurred primarily in the winter-spring. The $T$. rotula/T. gravida group was more common but less abundant than T. nordenskioeldii. It was present in $16.8 \%$ of samples with a maximum abundance of 689,000 cells/liter. This taxa was recorded every year and was more commonly seen in the late fall, winter and spring. Finally, the unidentified 
Thalassiosira spp. was the most common and abundant group observed. It was present in $78.0 \%$ of the weekly samples, with a maximum abundance of $1,683,000$ cells/liter. This group was recorded every year and was observed year round. The abundance and ubiquity of this group are likely a result of this group representing multiple species, which could not be identified due to LM limitations or counter ability.

\section{Sequencing Results}

$16,157,090$ sequence read pairs were obtained for this study. Sequences per sample ranged from 58,448 sequence read pairs to 281,234 sequence read pairs, with an average of 168,303 sequences per sample (Appendix 3). An average of 11,098 sequences per sample survived (6.6\%) the filtering and merging steps, with a range of 172 to 26,869 sequences per sample (Appendix 3). Despite a few samples with very low sequence survival rates, a majority of OTU rarefaction curves and species rarefaction curves terminated with an asymptote, indicating that sampling depth was appropriate for this study (Figure 3).

\section{Reference Database}

The ML tree for the $1552 \mathrm{bp} 18 \mathrm{~S}$ gene in Thalassiosira species showed moderate species resolution and bootstrap support (Figure 4). In contrast, the ML tree for the $420 \mathrm{bp} \mathrm{V4}$ region of the $18 \mathrm{~S}$ showed weaker support and lower species resolution (Figure 5). Some species were clearly resolved in both the V4 region and the full length $18 \mathrm{~S}$. For example, both the $18 \mathrm{~S}$ and $18 \mathrm{~S} \mathrm{~V} 4$ analyses supported a distinct clade comprised of $T$. guillardii, $T$. weissflogii and T. pseudonana. These three species are highly resolved and distinguishable at the $18 \mathrm{~S}$ and $18 \mathrm{~S}$ V4 fragments. 
Other species were not resolved as clearly in the 18S V4 tree, either due to variable sequences for one species not clustering together or due to multiple species sharing one common sequence. The first pattern is seen for T. anguste-lineata, T. minima, $T$. profunda and T. tenera, each of which has sequences which appear on more than one branch in the $18 \mathrm{~S}$ V4 ML tree. The $T$. tenera sequences cluster together at the whole $18 \mathrm{~S}$, indicating that this is one species. However, for T. anguste-lineata and T. profunda, the sequences also appear on different branches of the whole $18 \mathrm{~S}$ tree, meaning that the taxonomies for these species can't be clarified. The second pattern appears when there are no differences at the 18S V4 locus between or among species, meaning that the two species are unable to be resolved at this locus. These unresolved species pairs include T. nordenskioeldii and T. aestivalis, T. pacifica and T. aestivalis, and $T$. rotula and $T$. gravida.

\section{Mock Community Results}

Sequencing of the mock communities recovered all 9 species that had been added, including all four Thalassiosira species, as well as the other diatom species $(D$. brightwelli, S. marinoi, S. menzellii, ) and the raphidophyte (H. akashiwo). The dinoflagellate $(H$. triquetra) did not appear in sequencing results, as the primers do not amplify dinoflagellates. Initial results included OTUs for T. guillardii and T. oceanica, neither of which was added in the mock communities. Manual examination demonstrated that these sequences were comprised of sequence fragments from two species that were in the mock communities, meaning that they were chimeric. The purported T. oceanica OTU was comprised of a $120 \mathrm{bp}$ segment of the T. weissflogii 
sequence appended to a $260 \mathrm{bp}$ segment of T. anguste-lineata sequence. After chimeric species were filtered and removed using UCHIME denovo (Edgar 2011), all final sequences from the mock communities were identified as species which had been added to the mock communities. There were no sequences with unassigned taxonomy, verifying that the analysis methods accurately captured community composition of samples.

Among the DNA extraction triplicates for each of the four mock communities, composition did not vary significantly (ANOVA, $p>0.05$; Figure 6 ). Composition did not vary significantly among the three amplification triplicates performed on either the mock community sample (mock community 1$)$ or the field sample (12/30/2014) (ANOVA, $\mathrm{p}>0.05$ ). In contrast, observed mock community percent OTU composition was significantly different than the expected percent species composition used to create the mock communities ( $\chi$ square goodness-of-fit-test, $\mathrm{P}<0.001$; Figure 6 ). Since OTU composition did not adequately represent the actual species composition of the mock communities, sequence abundance of each OTU could not be used as an estimate of species abundance. As a result, species composition of the field samples was analyzed using presence/absence data.

\section{Field Sample Sequencing Results}

Fifteen Thalassiosira species were identified in the field samples (Table 4) in comparison to the three species identified through LM counts. In contrast to the mock community results, there were unidentified species remaining in the field sample sequences after taxonomy was assigned. These unidentified sequences were not used in downstream community analysis, since primers amplified all diatoms and 
raphidophytes in the samples. Of the fifteen Thalassiosira species identified in the sequence data, eight had not been identified historically using light microscopy in the Narragansett Bay Long-Term Phytoplankton Time Series: T. oceanica, T. guillardii, T. minima, T. tenera, T. angulata, T. aestivalis, T. tumida, T. concaviuscula and $T$. profunda. Five of these new records for Narragansett Bay have cell diameters under $15 \mu \mathrm{m}$ (Table 5), making them difficult to identify using light microscopy at 100x. The fifteen Thalassiosira species observed in the HTS results had different occurrence patterns (Figure 7), frequencies (Figure 8), and coexistence patterns (Figure 9). Some of the species only occurred during some months or years while others were more persistent. Seven of the least frequent species (T. aestivalis/T. nordenskioeldii, T. anguste-lineata, T. concaviuscula, T. eccentrica, T. oceanica, T. tenera, $T$. tumida) were not present every year. The remaining eight species ( $T$. angulata, T. guillardii, T. mimina, T. pacifica/T. aestivalis, T. profunda, T. pseudonana, T. punctigera, T. rotula/T. gravida) were present each year.

While 15 total species were observed, species richness varied from 1-8, meaning that some species did not co-occur. A clear seasonal pattern in richness was not observed. A maximum of eight species were observed in both January 2011 and May 2014. A species richness of 1 was most often observed in August ( $T$.

pseudonana, 2009; T. tenera, 2010; T. guillardii, 2012). Some species were more likely to co-occur than others but these patterns were not especially strong (Figure 8). At a $45 \%$ Bray Curtis similarity, one group of four species emerged: $T$. guillardii, $T$. minima, T. profunda and T. pseudonana. These species were all frequent and have small cell sizes (Table 5). T. guillardii and T. minima were the most likely species to cooccur, with a $70 \%$ Bray Curtis similarity. 
The majority of species were not very frequent (Figure 8); only two species ( $T$. guillardii, T. pseudonana) had frequencies above $40 \%$. Thalassiosira guillardii was the most frequent, appearing in $78.75 \%$ of field samples, followed by T. pseudonana (. T. minima and T. pseudonana were also quite frequent $(61.25 \%$ and $47.5 \%$ respectively). All other species had frequencies under 30\%. The least frequent species were T. tumida and T. eccentrica.

Seasonality of Thalassiosira community composition

To determine if there were similarities among species assemblages collected at different times of year, the Bray-Curtis similarity of species composition between months was calculated. A multi-dimensional scaling plot of the monthly pair-wise comparisons revealed three distinct assemblages at a similarity value of 55\%: a winter-spring assemblage (January, February, March, April), a summer assemblage (May, June, July, August, September) and a fall assemblage (October, November, December) (Figure 10). These seasonal groupings roughly corresponded with two groups of field samples that diverge at a 35\% Bray-Curtis similarity (Figure 11). One grouping at this $35 \%$ similarity level consists mainly of the winter-spring samples and the other grouping consists primarily of the summer samples. The fall samples seem to be scattered between both groups.

Several species were observed more often during warmer months. T. angulata occurred mostly from March-July. T. oceanica was most likely to occur in April May, but occurred sporadically in other months (Figure 12). T. tenera occurred in July through October in all years except 2012 and 2014. T. rotula/T. gravida occurred 
most often in April-June and never in the months of February and September through November (Figure 12).

Other species were more often seen during the fall, winter and spring (Figure 12). When the T. nordenskioeldii/T. aestivalis OTU was present, it occurred during the months of December-April. T. eccentrica only occurred during the months of OctoberDecember. The T. pacifica/T. aestivalis OTU never occurred in the summer months (from May - September). T. punctigera also never appeared in the summer months (from June - August) or in March. It was most likely to occur in late fall (October December).

However, seasonal patterns were not apparent for all of the species studied, including T. anguste-lineata, T. concaviuscula and T. profunda. A final subset of the annually occurring species were persistent throughout the year. T. pseudonana occurred year round with the exception of the month of February (Figure 12). It was most likely to occur from June - September. T. guillardii was observed in samples from all twelve months, although its probability of occurrence was slightly higher in the winter. Likewise, T. minima was also observed in samples from all twelve months, with a higher occurrence probability in the winter (100\% for December and January during the study period).

\section{Species Specific Environmental Ranges}

In addition to variation in seasonal occurrence patterns, species also had variable observed temperature and salinity ranges (Figure 13). Ranges are not reported for T. tumida, as this species was only observed on one occasion (conditions were $14.76^{\circ} \mathrm{C}$ and $\left.30.7 \mathrm{ppm}\right)$. Many species had broad temperature ranges, but a few species 
had more specific temperature ranges. The T. nordenskioeldii/T. aestivalis OTU had a lower temperature range $\left(0.5-8.5^{\circ} \mathrm{C}\right) . T$. eccentrica was observed only in midtemperatures $\left(5.5-17.07^{\circ} \mathrm{C}\right)$, while $T$. tenera was only observed in warm temperatures $\left(18.1-24.6^{\circ} \mathrm{C}\right)$.

More variation was observed in salinity ranges. Some of the most frequent species had the broadest salinity ranges, including T. guillardii (18.6-32 ppt), T. minima (18.6-32 ppt) and T. pacifica/T. aestivalis (18.6-31.41 ppt). Half of the species were only observed at salinities over $24 \mathrm{ppt}$ (T. concaviuscula, T. eccentrica, $T$. nordenskioeldii/T. aestivalis, T. oceanica, T. profunda, T. punctigera, T. tenera and T. tumida). All species were observed at salinities of over $30 \mathrm{ppt}$.

\section{Environmental Factors}

Environmental factors in Narragansett Bay varied widely from December 2008 - December 2014. Surface temperature was strongly seasonal and ranged from 0.5 $24.6^{\circ} \mathrm{C}$. Average daily PAR was also seasonal, varying from $16.21-572.05 \mathrm{mmol} / \mathrm{m}^{2}$. Salinity averaged 29 ppt, with a range of $18.6-32.39$ ppt. Chlorophyll $a$ had a minimum value of $0.23 \mu \mathrm{g} / \mathrm{L}$ and a maximum of $29.8 \mu \mathrm{g} / \mathrm{L}$ during a large phytoplankton bloom in April 2010. Dissolved inorganic nitrogen (DIN) ranged from $0.14-15.8 \mu \mathrm{M}$, dissolved inorganic phosphorus (DIP) ranged from $0.04-1.87 \mu \mathrm{M}$ and silicate ranged from $0.05-38.12 \mu \mathrm{M}$.

A principal components analysis (PCA) of the environmental factors separated the sample dates roughly by season (Figure 14). The first PC axis explained $40.1 \%$ of the variation and separated samples primarily by DIP, but also by DIN, $\mathrm{Si}, \mathrm{Chl} a$, and surface salinity. Higher nutrients and lower chl $a$ were associated with summer and 
fall samples. The second PC axis explained $25.4 \%$ of the variation and differentiated samples by surface temperature and average daily PAR. Higher temperatures and average daily PAR were associated with summer samples, while lower temperatures and PAR were associated with winter samples. Surface temperature was the most highly correlated environmental factor and explained $24.6 \%$ of the Thalassiosira community variation through BEST analysis (Table 6).

\section{Morphological Variation of Thalassiosira Cells}

A preserved sample was examined to verify species presence when unresolved species OTUs were present in the HTS results. One sample from January 11, 2011 was chosen when both the T. nordenskioeldii/T. aestivalis and the T. pacifica/T. aestivalis OTUs were present in the HTS sequence results (Figure 15). Hexagonal shaped cells with depressed valve faces that appear to be $T$. nordenskioeldii are visible (Figures 14a, 14b). Cells with several closely spaced marginal processes are also visible, which is indicative of T. aestivalis or T. pacifica (Figures 14c, 14d). Identifications are based on Hasle (1978). 


\section{DISCUSSION}

Use of the V4 region as a barcoding gene for the genus Thalassiosira

The HTS results uncovered greater diversity than found through traditional light microscopy methods and this research supports using the 18S V4 locus as a barcode gene for the Thalassiosira genus of diatoms. As in Luddington et al. (2011), the 18S V4 barcode here differentiated between several species within a closely related diatom genus. The $18 \mathrm{~S}$ V4 maximum likelihood tree resulted in one strongly supported clade consisting of T. weissflogii, T. guillardii, and T. pseudonana. This is similar to results in Hoppenrath et al. (2007), which found one clade consisting of $T$. pseudonana and Detonula confervacea, and another clade consisting of T. weissflogii, T. guillardii and T. oceanica (AF374479). The 18S V4 ML tree constructed here shows a different $T$. oceanica strain (DQ514878) which does not cluster with $T$. weissflogii and T. guillardii. This is in accordance with a phylogeny constructed from both SSU and partial LSU nuclear DNA by Alverson et al. (2007). Finally, the larger clade found in the ML tree contains all other Thalassiosira species, in accordance with Kaczmarska et al. (2006), Hoppenrath et al. (2007), and Alverson et al. (2007).

Overall, the ML tree constructed using the reference database sequences used here appears to accurately represent the paraphyly of this genus.

Understanding the limitations of a method is important. The reference database used here does not perfectly resolve all Thalassiosira species, since some species have identical sequences at this locus (T. nordenskioeldii and T. aestivalis, T. pacifica and T. aestivalis), while other species are very closely related and therefore, indistinguishable (T. rotula and T. gravida). Additionally, just 31 Thalassiosira 
species have 18S V4 sequences at this locus available in GenBank, meaning that dozens of Thalassiosira species do not yet have sequences at this locus. This limitation is present for all barcoding loci and will improve as more sequencing is completed for taxonomically identified species.

The mock community experiment was a valuable way to verify this method and validate the bioinformatics pipeline. While the trimming performed here was very stringent, the mock community results validated the accuracy of the sequence processing pipeline, particularly with regards to removal of chimeric sequences, thus enabling accurate interpretation of these field sample data. Not only did this verification experiment shed light on $18 \mathrm{~S}$ copy number variation, but it allowed for easy exploration of chimera contamination in the results and demonstrated the amount of technical variation inherent to this method.

A significant potential limitation of the HTS approach is variation in $18 \mathrm{~S}$ copy number variation. $18 \mathrm{~S}$ gene copy number can vary from 1 to 12,000 in phytoplankton species, and more specifically, can vary by an order of magnitude between Thalassiosira species (Zhu et al. 2005) and is not known for the large majority of Thalassiosira species. Copy number variation was seen in the mock community results. Mock community sequence percent composition did not equal known species abundances in each community. While variation in DNA extraction or amplification could cause these differences in expected versus actual results, the triplicate extraction samples and triplicate amplification samples were not significantly different from each other. Therefore, small subunit (SSU) rDNA copy number is likely partially responsible for this inequality. While triplicate variation in mock communities 3 and 4 
is not statistically significant, it is greater than triplicate variation seen in mock communities 1 and 2, which is minimal. This variation is too large to be easily explained by SSU rDNA copy number, and a satisfactory alternate explanation is not readily apparent. Other factors such as PCR bias and sequencing bias, or methodological error may be at play. As a result, care is necessary in interpreting SSU rDNA sequence abundance for diatoms, as sequence abundance is not likely to reflect species abundance.

Chimeric sequences were found in the mock community sequences results. When species were identified which had not been added, it was very easy to pinpoint the issue. If a mock community control did not exist, this problem may have been overlooked in field samples. Chimeric sequences can arise during PCR (Smyth et al. 2010) if the elongation step is aborted while a sequence has only partially been extended. If this partial sequence misprimes another sequence during a following PCR cycle, the resulting sequence can be partially from one species and partially from another. Therefore, it is valuable to maintain a control when sequencing field samples to help screen for issues such as chimeric sequences and running final OTUs through a chimera filter such as UCHIME is recommended.

Finally, the mock community demonstrated the technical replication of this method. The triplicate amplifications of a mock community sample and a field sample all resulted in identical species compositions. Additionally, our triplicate mock community extractions also all resulted in identical species compositions. When compared to other next generation desktop sequencers, Illumina MiSeq generates the most data with the lowest error rate (Loman et al. 2012). Canesi and Rynearson (in 
press) tested triplicate extraction, amplification and Illumina Miseq sequencing with 28S ribosomal DNA from Skeletonema diatoms and found low levels of variation (coefficient of variance less than 15\%) were associated with Illumina sequencing, which is why triplicate sequencing tests were not completed in this study.

\section{Thalassiosira diversity}

The diversity of Thalassiosira species in Narragansett Bay is greater than previously realized. The fifteen species found through HTS represents a five-fold increase in number of Thalassiosira species found using LM during the same time period. Eight of the fifteen species identified using HTS had not been historically documented in the Narragansett Bay Long-Term Phytoplankton Time Series.

Realistically, seven new Thalassiosira species are identified here for Narragansett Bay and one new species record (T. tumida) is questionable, which will be discussed below.

If all Thalassiosira species recorded using both light microscopy and high throughput sequencing in the Phytoplankton Time Series from 1959 through the present are tallied, 18 Thalassiosira species are known to exist in this estuary. This is comparable to Thalassiosira species diversity found in other global estuaries. A study by Hoppenrath et al. (2007) using light and scanning electron microscopy methods found 21 Thalassiosira species in the North Sea. Similarly, using light and scanning electron microscopy methods, Harris et al. (1995) identified 18 Thalassiosira taxa in a Scottish sea loch. The results here are comparable to both the results from Hoppenrath et al. (2007) and Harris et al. (1995) but were obtained without using scanning 
electron microscopy. The $18 \mathrm{~S}$ V4 barcode can assess diversity within a closely related diatom genus similarly to SEM methods, but less time and expertise is required.

Several of the newly recorded species in Narragansett Bay are small $(<15 \mu \mathrm{m})$ (T. guillardii, T. minima, T. oceanica, T. profunda; Table 5) which may explain why they were not identified using LM at 100x. Hasle (1978) states that T. profunda is not identifiable through LM. However, their presence in an estuary is not unprecedented. T. guillardii, the most frequent species seen in these results, is very frequent and abundant in a Spanish estuary (Trigueros et al. 2001). T. guillardii is also recorded in several British estuaries (Belcher and Swale 1986). T. oceanica has been identified in Loch Creran in Scotland (Harris et al. 1995). Some of the larger newly recorded species for Narragansett Bay are also observed in other estuaries. T. profunda, $T$. minima, and T. tenera are recorded in British estuaries (Belcher and Swale 1986) and T. angulata, and T. concaviuscula have been collected in Loch Creran, Scotland (Harris et al. 1995).

The presence of T. tumida in Narragansett Bay is surprising. It was only present in 1 out of 80 field samples and was the least frequent species in the HTS results. This species is known to only exist in the Southern Ocean (Tomas 1997). While this could suggest that the range of this species is greater than previously thought, the sample with T. tumida was collected in the summer (6/19/2013) when water temperatures was $20.0^{\circ} \mathrm{C}$, well above the recorded tolerance of this species. It is more likely that another Thalassiosira species shares the same 18S V4 sequence as $T$. tumida at this locus, similar to the very closely related $18 \mathrm{~S} \mathrm{~V} 4$ sequences for $T$. rotula 
and $T$. gravida also in these results. Since $18 \mathrm{~S}$ V4 sequences are lacking for many Thalassiosira species, it is likely that this OTU was incorrectly assigned here.

\section{Historical data comparisons}

Since this study builds upon a long running time series, it is valuable to compare these most recent HTS data with the historical record. Our recent data both include species that were important in the past and exclude some historically recorded species. Three species (T. hyalina, T. kushirensis and T. decipiens) recorded historically in the Narragansett Bay Long-Term Time Series were not detectable using our 18S HTS methods (Table 4). Two of these species (T. kushirensis and T. decipiens) do not have reference sequences at the 18s V4 locus and were therefore not included in the reference database used in this study. A 333bp partial 18S V4 sequence does exist in GenBank for T. hyalina (JX437383.1), which is shorter than the amplicon used here. If reference sequences for these species are added in GenBank, this data can be tested for their presence. Our results did include sequences which were not assigned taxonomy from the reference database. These unidentified sequences may include additional Thalassiosira species, but also contain other phytoplankton species. The primers used here amplify other diatoms and raphidophytes (as in the mock community results presented here), and Narragansett Bay is home to numerous diatom genera, which were also amplified in the field samples but not analyzed for this study.

Of the historically recorded species that were found in the recent HTS results, T. nordenskioeldii is perhaps the most notable. As the fifth most abundant diatom 
species from 1959-1980, Karentz and Smayda (1984) identified T. nordenskioeldii as moderately persistent and as a characteristic winter species in Narragansett Bay. From 1959-1980, T. nordenskioeldii occurred every year, although annual abundance appeared to vary on a 5 year cycle. This persistent pattern contrasts with more recent results. From 1999-2008, T. nordenskioeldii was the eighth most abundant species in LM counts (Windecker 2010) and 20th most frequent species. T. nordenskioeldii no longer appears every year; it is absent from LM counts in 1999, 2006 and 2013.

Our HTS data can provide additional information regarding the recent frequency and seasonality of T. nordenskioeldii from December 2008-December 2014. Unfortunately, while our 18S V4 data could not be used to distinguish between $T$. nordenskioeldii and T. aestivalis, the environmental data associated with these sequences does help differentiate the species to some degree. The temperature ranges for T. nordenskioeldii and T. aestivalis do not overlap very much. T. nordenskioeldii is a cold water species $\left(3.1-15^{\circ} \mathrm{C}\right.$; Karentz and Smayda 1984) while T. aestivalis is a temperate species. The temperature range for the T. nordenskioeldii/T. aestivalis OTU was $0.5-8.5^{\circ} \mathrm{C}$, suggesting that the species observed here may be $T$. nordenskioeldii. The preserved cell images (Figure 14) also include T. nordenskioeldii. While our results are unable to definitively distinguish $T$. nordenskioeldii from $T$. aestivalis, these additional data make it more plausible that this OTU may be only $T$. nordenskioeldii. Since T. aestivalis has not historically been identified in the Phytoplankton Time Series, we are unable to confirm its identification and occurrence in Narragansett Bay. 
In our HTS results, the T. nordenskioeldii/T. aestivalis OTU was not present from 2012-2013, and was only the eighth most frequent species identified in the Thalassiosira genus. The absence from 2012-2013 is in accordance with the LM count data, validating the decrease in persistence for this species. While this genetic analysis does not include cell abundance, it is known that mean total diatoms in the winter at Station II have displayed a downward trend from 1959-1980 (Smayda 1998). Windecker (2010) notes that several notable diatom species, including Skeletonema and Thalassiosira, declined dramatically between 1959-1980 and 1999-2008. It is possible that this trend continued through 2014 , and is reflected by the decreased frequency of T. nordenskioeldii.

Other species with historic records in Narragansett Bay are T. rotula, $T$. pseudonana, and Thalassiosira sp. T. rotula was the $18^{\text {th }}$ most abundant phytoplankton species and 3rd most abundant Thalassiosira species from 1959-1980 (Karentz and Smayda 1984). From 2008-2014, it was still very common and the $T$. rotula/T. gravida OTU appeared annually in the HTS results and was more likely to occur in the spring and summer. $T$. rotula historically displayed a yearly maximum in the fall. T. gravida was less abundant than T. rotula in the 1959-1980 time series records $\left(36^{\text {th }}\right.$ most abundant phytoplankton; $5^{\text {th }}$ most abundant Thalassiosira $)$ but no seasonality information is given in Karentz and Smayda (1984). The LM counts from December 2008 - December 2014 include records of T. rotula/T. gravida during all months with the exception of February with the highest abundances occurring in December and January. So, while this OTU is more likely to occur in the spring and summer, highest abundances are now seen in the winter. This appears to be an 
example of a species with a broad thermal tolerance that can maintain a low population year round, punctuated by opportunistic, winter blooms. These winter $T$. rotula/T. gravida blooms do not appear to be annual and are recorded in the LM counts only for 2011, 2012, and 2014. This contrasts with the historic fall abundance peaks, and perhaps represents a shift in the timing of this species. Alternatively, since seasonality is not specified historically for $T$. gravida, this possibly may not represent a shift but rather the presence of $T$. gravida with $T$. rotula.

T. pseudonana occurred frequently in the HTS results and is also an important model organism with a fully sequenced genome (Armbrust et al. 2004). It was the $39^{\text {th }}$ most abundant phytoplankton species and $6^{\text {th }}$ most abundant Thalassiosira species recorded in the time series from 1959-1980 (Karentz and Smayda 1984). Since $T$. pseudonana was not one of the top numerically dominant species observed from 19591980, there is no published data regarding the timing or seasonality of this species. However, this is the last published occurrence of T. pseudonana in the time series. Likely due to its small size, it has not been recorded in the time series LM counts since 1999. Globally, earlier references only recorded this species rarely (i.e. Muylaert and Sabbe 1996, Belcher and Swale 1986). More recently, however, T. pseudonana was recorded as a bloom forming species in the Bilbao estuary (Hevia-Orube et al. 2015) and a dominant spring taxon in Chesapeake Bay (Marshall et al. 2006). Our results combined with these more recent observations suggest that this species could be an important or at least a more frequent contributor to estuarine phytoplankton communities than currently recognized. 
The final historic Thalassiosira record of note is Thalassiosira sp., the sixth most abundant phytoplankton species ( $2^{\text {nd }}$ most abundant Thalassiosira) from 19591980 (Karentz and Smayda 1984). This species was characterized as a small $(\sim 10 \mu \mathrm{m}$ in diameter), unidentified Thalassiosira species that appeared in Narragansett Bay beginning in 1967 and became both frequent and common. Our HTS results identified several small, very frequent Thalassiosira species that had not been previously identified in the Phytoplankton Time Series, including Thalassiosira guillardii (4$14 \mu \mathrm{m})$ and Thalassiosira minima $(5-15 \mu \mathrm{m})$, either of which may be the species discussed historically.

\section{Factors affecting species composition}

Seasonal patterns are apparent when looking at individual species (as in the discussions of $T$. nordenskioeldii and $T$. rotula/T. gravida above) but as whole, seasonality does not fully explain Thalassiosira community composition (Figure 10). Field samples grouped into three rough seasonal assemblages by month, but when comparing by sample day, these patterns are difficult to ascertain. The dendrogram based on Bray-Curtis similarity breaks the samples down into two main groups at only a $35 \%$ similarity level. One group contains most of the summer sample dates while the other contains most of the winter/spring sample dates. Fall sample dates are spread between both groups. This pattern is not very strong and may be driven by the seasonality of a few key species, while other sporadic species and persistent species may dilute the seasonality signal of the entire community. The contributions of the seasonal species (T. nordenskioeldii, T. eccentrica, T. punctigera, T. rotula/T. gravida) are perhaps more apparent when samples are grouped by month, explaining why the 
three seasonal groups are more apparent in Figure 10 than in Figure 11, which considers samples individually. Temperature explains $24.6 \%$ of the variation in community composition according to the BEST analysis, which leaves the majority of the variation due to other factors.

If seasonality does not entirely explain the community composition of the Thalassiosira species seen in Narragansett Bay, then what factors control the patterns reported here? Additional factors not analyzed in this study include large-scale climatic processes, top-down control, other loss factors and biological competition. For example, larger scale climatic processes including the Gulf Stream and the North Atlantic Oscillation are known to impact size and timing of Narragansett Bay summer Skeletonema blooms (Borkman 2009, Smayda and Borkman 2009). These regional ocean-atmospheric patterns may also impact other diatoms, including Thalassiosira species. On a much smaller scale, microzooplankton grazers consume an average of 96\% of primary production in Narragansett Bay (Lawrence and Menden-Deuer 2012). Grazers also preferentially select particular prey which in turn can structure the phytoplankton community. Microzooplankton in Chesapeake Bay selectively graze on picophytoplankton $(<2 \mu \mathrm{m})$ (Sun et al. 2007). The species in this study range in size from $1.8 \mu \mathrm{m}-186 \mu \mathrm{m}$, and may be under differential grazing pressure. Another noteworthy annual grazer in Narragansett Bay is Mnemiopsis leidyi. M. leidyi exerts significant control on the plankton community in Narragansett Bay. In four years out of a six year study (1972-1977), a summer M. leidyi bloom was correlated with rapid declines in both the zooplankton and phytoplankton communities and variations in the summer abundance of diatom Skeletonema sp. correlated with the size of the M. leidyi 
pulse (Deason and Smayda 1981). M. leidyi blooms may be occurring earlier in the spring and increasing in abundance as water temperatures rise with climate change (Sullivan et al. 2001), which may impact Thalassiosira species.

Other loss factors affecting diatom communities are cell lysis, sinking and advection (as reviewed in Sarthou et al. 2004). These three factors may be structuring the Thalassiosira population in Narragansett Bay as these three processes can differentially affect species based on factors including size, density, and morphology (Smayda 1969, Veldhuis et al. 2001, Miklasz and Denny 2010). Spore formation in particular contributes to Thalassiosira loss through sinking (as reviewed by McQuoid and Hobson 1996). Advection can also seed diatom populations from surrounding water masses. Benthic diatom populations and pelagic diatom populations are both able to seed diatom blooms, but may result in divergent population structures (McQuoid and Godhe 2004), which may explain the lack of clear seasonal Thalassiosira assemblages observed here.

Finally, only one diatom genus was examined here while at least 30 diatom genera have been observed in the Long-Term Phytoplankton Time Series, along with at least 10 dinoflagellate genera and 10 flagellate genera (Windecker 2010). The additional species that make up the entire phytoplankton community could affect the Thalassiosira community structure through resource competition. Alternately, diatoms may co-occur through resource partitioning. For example, metatranscriptome data from diatoms in Narragansett Bay revealed that Skeletonema sp., the most abundant diatom in the bay, and $T$. rotula utilize different nitrogen and phosphate metabolic pathways, perhaps allowing these species to partition resources (Alexander et al. 
2015). These complex environment-species-species interactions were not examined in this study, but clearly are a part of the Narragansett Bay ecology. Future work on community wide processes in Narragansett Bay may provide insight into additional controls on Thalassiosira populations.

\section{Conclusions}

The high throughput sequencing approach using the 18s V4 locus is a powerful tool for exploring diversity and seasonal occurrence patterns for diatom genera such as Thalassiosira that harbor great species diversity and are morphologically similar. Thalassiosira species diversity in Narragansett Bay is greater than previously recognized. Much of this newly found diversity can be attributed to several smaller sized species that are very frequent and have been overlooked using light microscopy methods. Thalassiosira species have a rough seasonal pattern grouped by winterspring, summer and fall, and only $25 \%$ of the Thalassiosira species composition is explained by the physical and chemical environmental factors in this study. Other factors, such as large scale climactic processes, predation effects, sinking rates, autolysis and community competition, may be contributing to Thalassiosira species composition in Narragansett Bay. In comparison to historical data, the frequency of important bloom species such as $T$. nordenskioeldii may be in decline, while T. rotula timing may have shifted. 


\section{TABLES}

Table 1: Five candidate diatom barcodes were considered for this study. For each potential barcode, the reference, primer pair and number of Thalassiosira species available in GenBank are given.

\begin{tabular}{|c|c|c|c|c|}
\hline Barcode & Reference & Forward Primer & Reverse Primer & $\begin{array}{l}\text { \# Species } \\
\text { in } \\
\text { GenBank }\end{array}$ \\
\hline $\begin{array}{l}18 \mathrm{~S}(\mathrm{~V} 4 \\
\text { region) }\end{array}$ & $\begin{array}{l}\text { Zimmerman et al. } \\
\text { 2011, Luddington et } \\
\text { al. } 2012\end{array}$ & $\begin{array}{l}\text { D512 } \\
\text { ATTCCAGCTCCAAT } \\
\text { AGCG }\end{array}$ & $\begin{array}{l}\text { D978 } \\
\text { GACTACGATGGTAT } \\
\text { CTAATC }\end{array}$ & 31 \\
\hline ITS2 & Chappell et al. 2013 & $\begin{array}{l}\text { RCGAAYTGCAGAA } \\
\text { CCTCG }\end{array}$ & $\begin{array}{l}\text { TACTYAATCTGAGA } \\
\text { TYCA }\end{array}$ & 5 \\
\hline ITS2 & $\begin{array}{l}\text { Moniz and } \\
\text { Kaczmarska 2010, } \\
\text { White et al. 1990 }\end{array}$ & $\begin{array}{l}\text { TCCGTAGGTGAAC } \\
\text { CTGCGG }\end{array}$ & $\begin{array}{l}\text { TCCTCCGCTTATTG } \\
\text { ATATGC }\end{array}$ & 5 \\
\hline $\begin{array}{l}18 \mathrm{~S} \text { (V9 } \\
\text { region) }\end{array}$ & $\begin{array}{l}\text { Amaral-Zettler et al. } \\
2007\end{array}$ & $\begin{array}{l}\text { 1380F } \\
\text { CCCTGCCHTTTGTA } \\
\text { CACAC }\end{array}$ & $\begin{array}{l}\text { 1510R } \\
\text { CCTTCYGCAGGTTC } \\
\text { ACCTAC }\end{array}$ & 21 \\
\hline $\begin{array}{l}18 \mathrm{~s}(\mathrm{~V} 7 \\
\text { region) }\end{array}$ & Gast et al. 2004 & $\begin{array}{l}\text { 960F } \\
\text { GGCTTAATTTGACT } \\
\text { CAACRCG }\end{array}$ & $\begin{array}{l}\text { Diatom1R } \\
\text { ATGCAGATTGATG } \\
\text { ATCTGCG }\end{array}$ & 30 \\
\hline
\end{tabular}


Table 2: Accession numbers, references, and strain (if known) are given for all of the reference 18S V4 genes used in this study. Sequences were accessed through NCBI GenBank. Numbers given after Thalassiosira species with $>1$ sequence in this reference database are used to differentiate sequences.

\begin{tabular}{|c|c|c|c|}
\hline Species & $\begin{array}{l}\text { Accession } \\
\text { Number }\end{array}$ & Reference & $\begin{array}{l}\text { Strain } \\
\text { (if known) }\end{array}$ \\
\hline D. brightwellii & FJ266033 & Rynearson et al., 2009 & \\
\hline H. akashiwo & KT163009 & Harvey et al., 2015 & \\
\hline S. marinoi & AJ632216 & Sarno et al., 2005 & \\
\hline S. menzellii & AJ535168 & $\begin{array}{l}\text { Medlin and Kaczmarska, } \\
\text { unpublished, } 2002\end{array}$ & CCMP 790 \\
\hline T. aestivalis 1 & DQ093369 & Kaczmarska et al., 2006 & CCMP 975 \\
\hline T. aestivalis 2 & DQ514873 & Alverson et al., 2007 & ССМР976 \\
\hline T. angulata & DQ514867 & Alverson et al., 2007 & BEN02-35 \\
\hline T. anguste-lineata 2 & DQ514865 & Alverson et al., 2007 & BEN02-30 \\
\hline T. anguste-lineata 1 & AJ810854 & Hoppenrath et al., 2007 & \\
\hline T. antarctica & DQ514874 & Alverson et al., 2007 & CCMP982 \\
\hline T. concaviuscula 1 & AJ810857 & Hoppenrath et al., 2007 & \\
\hline T. concaviuscula 2 & HM991689 & $\begin{array}{l}\text { Park, Jung, Ki and Lee, } \\
\text { unpublished, } 2010\end{array}$ & \\
\hline T. eccentrica 1 & DQ514868 & Alverson et al., 2007 & BER02-9 \\
\hline T. eccentrica 2 & X85396 & Medlin et al., 1996 & \\
\hline T. gravida 1 & JX069323 & Whittaker et al., 2012 & \\
\hline T. gravida 2 & JX069325 & Whittaker et al., 2012 & \\
\hline T. gravida 3 & JX069333 & Whittaker et al., 2012 & \\
\hline T. guillardii 1 & AF374478 & Armbrust and Galindo, 2001 & CCMP988 \\
\hline T. guillardii 2 & DQ514869 & Alverson et al., 2007 & CC-03-04 \\
\hline T. guillardii 3 & DQ514875 & Alverson et al., 2007 & CCMP988 \\
\hline T. minima 1 & DQ514876 & Alverson et al., 2007 & ССМР990 \\
\hline T. minima 2 & JN934676 & $\begin{array}{l}\text { Balzano, Fourvil, Siano, Percopo, } \\
\text { Chanoine, Sarno and Vaulot, } \\
\text { unpublished, } 2011\end{array}$ & \\
\hline T. minuscula 1 & DQ514887 & Alverson et al., 2007 & FB02-31 \\
\hline T. minuscula 2 & HM991694 & $\begin{array}{l}\text { Park, Jung, Ki and Lee, } \\
\text { unpublished, } 2010\end{array}$ & \\
\hline T. nordenskioeldii 1 & DQ093365 & Kaczmarska et al., 2006 & СCMP997 \\
\hline T. nordenskioeldii 2 & JF794045 & Balzano et al., 2012 & \\
\hline T. oceanica & DQ514878 & Alverson et al., 2007 & CCMP1001 \\
\hline T. $c f \cdot$ pacifica & DQ514888 & Alverson et al., 2007 & FB02-35 \\
\hline T. profunda 1 & AM235383 & Kaczmarska et al., 2006 & POMX \\
\hline T. profunda 2 & KC284713 & Alverson 2013 & \\
\hline T. pseudonana 1 & AF374481 & Armbrust and Galindo, 2001 & CCMP1335 \\
\hline T. pseudonana 2 & DQ093367 & Kaczmarska et al., 2006 & \\
\hline T. punctigera & AJ810856 & Hoppenrath et al., 2007 & CCMP1007 \\
\hline T. rotula 1 & AF374480 & Armbrust and Galindo, 2001 & \\
\hline
\end{tabular}




\begin{tabular}{|c|c|c|c|}
\hline T. rotula 2 & AF462058 & $\begin{array}{l}\text { Cordevant and Lange, } \\
\text { unpublished, } 2001\end{array}$ & CCMP1647 \\
\hline T. rotula 3 & DQ514884 & Alverson et al., 2007 & CCMP1647 \\
\hline T. rotula 4 & JX069326 & Whittaker et al., 2012 & CCMP1812 \\
\hline T. rotula 5 & JX069328 & Whittaker et al., 2012 & \\
\hline T. rotula 6 & X85397 & Medlin et al., 1996 & CCMP1018 \\
\hline T. tenera 1 & AJ810858 & Hoppenrath et al., 2007 & \\
\hline T. tenera 2 & HM991701 & $\begin{array}{l}\text { Park, Jung, Ki and Lee, } \\
\text { unpublished, } 2010\end{array}$ & \\
\hline T. tumida & DQ514890 & Alverson et al., 2007 & \\
\hline T. weissflogii 1 & AF374477.2 & Armbrust and Galindo, 2001 & LA09-20 \\
\hline T. weissflogii 2 & KF733529 & Hu et al., 2014 & \\
\hline T. weissflogii 3 & GU594641 & Cleary et al., 2012 & \\
\hline T. weissflogii 4 & AY485445 & Damste et al., 2004 & \\
\hline
\end{tabular}


Table 3: Percent composition of each mock community (MC1-4). In each mock community, 9 species were added in varying percentages of cell abundance. The strains and location of isolation are given for each species.

\begin{tabular}{lllcccc}
\hline Species & Strain & Location & MC1 & MC2 & MC3 & MC4 \\
\hline \hline T. anguste-lineata & NBN & Narragansett Bay & 9.1 & 18.4 & 13.9 & 2.5 \\
T. weissflogii & CCMP 1336 & Long Island Sound & 9.1 & 5.1 & 13.9 & 2.5 \\
T. rotula & NBA & Narragansett Bay & 18.2 & 20.4 & 27.8 & 47.5 \\
T. pseudonana & CCMP 1007 & Chincoteague, Virginia & 9.1 & 5.1 & 13.9 & 22.5 \\
D. brightwellii & MV1 & Martha's Vineyard & 10.9 & 10.2 & 13.9 & 5.0 \\
S. marinoi & CCMP 1332 & Connecticut & 10.9 & 10.2 & 4.2 & 5.0 \\
S. menzelii & CCMP 793 & Falmouth, Massachusetts & 10.9 & 10.2 & 4.2 & 5.0 \\
H. akashiwo & CCMP 3374 & Narragansett Bay & 10.9 & 10.2 & 4.2 & 5.0 \\
H. triquetra & CCMP 448 & Falmouth, Massachusetts & 10.9 & 10.2 & 4.2 & 5.0
\end{tabular}


Table 4: Thalassiosira species identified historically (1959-1980) through LM counts and recently (2008-2014) using light microscopy (LM) and high throughput sequencing (HTS). $\mathrm{X}=$ identified; * = indistinguishable from other species by this method; - = unable to be detected (sequence not available in reference database); blank $=$ not detected by these methods. Note: T. tumida was recovered in sequence results but this record is questionable and not included in the total species count for Narragansett Bay. See discussion on page 27.

\begin{tabular}{lccc}
\hline & $\begin{array}{c}\text { Time Series } \\
1959-1980 \\
\text { and 1999-2008 }\end{array}$ & $\begin{array}{c}\text { Time Series } \\
\text { Dec. 2008 - } \\
\text { Dec. 2014 }\end{array}$ & $\begin{array}{c}\text { HTS } \\
\text { Dec 2008 - } \\
\text { Dec 2014 }\end{array}$ \\
\hline \hline T. aestivalis & & & $*$ \\
T. angulata & & & $\mathrm{X}$ \\
T. anguste-lineata & $\mathrm{X}$ & & $\mathrm{X}$ \\
T. concaviuscula & & & $\mathrm{X}$ \\
T. decipiens & $\mathrm{X}$ & & - \\
T. eccentrica & $\mathrm{X}$ & & $\mathrm{X}$ \\
T. gravida & $\mathrm{X}$ & $*$ & $*$ \\
T. guillardii & & & $\mathrm{X}$ \\
T. hyalina & $\mathrm{X}$ & & - \\
T. kushirensis & $\mathrm{X}$ & & - \\
T. minima & & & $\mathrm{X}$ \\
T. nordenskioeldii & $\mathrm{X}$ & $\mathrm{X}$ & $*$ \\
T. oceanica & & & $\mathrm{X}$ \\
T. pacifica & $\mathrm{X}$ & & $\mathrm{X}$ \\
T. profunda & & & $\mathrm{X}$ \\
T. pseudonana & $\mathrm{X}$ & & $\mathrm{X}$ \\
T. punctigera & $\mathrm{X}$ & $\mathrm{X}$ & $\mathrm{X}$ \\
T. rotula & $\mathrm{X}$ & $*$ & $\mathrm{X}$ \\
T. spp & $\mathrm{X}$ & $\mathrm{X}$ & \\
T. tenera & & & $\mathrm{X}$ \\
T. tumida & & & \\
& & & \\
\hline
\end{tabular}


Table 5: Cell diameter in microns and species range is presented for all Thalassiosira species recorded in the 2008-2014 sequence data. All information is from Tomas (1997) except where noted.

\begin{tabular}{|c|c|c|}
\hline Species & Cell diameter $(\mu \mathrm{m})$ & Range \\
\hline T. aestivalis & $14-56$ & Warm water region to temperate \\
\hline T. angulata & $12-39$ & $\begin{array}{l}\text { Cold to temperate waters (Hoppenrath et al. } \\
\text { 2007) }\end{array}$ \\
\hline T. anguste-lineata & $14-78$ & Cosmopolitan \\
\hline T. concaviuscula & 14-56 (Hoppenrath et al. 2007) & $\begin{array}{l}\text { Neritic, cold to temperate waters } \\
\text { (Hoppenrath et al. 2007) }\end{array}$ \\
\hline T. eccentrica & $15-110$ & Cosmopolitan (exclusive polar zones) \\
\hline T. guillardii & 4-14 (Hasle 1978) & $\begin{array}{l}\text { Inland and marine/brackish coastal waters } \\
\text { (Hasle 1978) }\end{array}$ \\
\hline T. minima & $5-15$ & Cosmopolitan (exclusive polar zones) \\
\hline T. nordenskioeldii & $10-50$ & Cold to temperate, northern hemisphere \\
\hline T. oceanica & $3-12$ & Mainly warm water region \\
\hline T. pacifica & $7-46$ & Cosmopolitan (exclusive polar zones) \\
\hline T. profunda & 1.8-5 (Belcher and Swale 1986) & Cosmopolitan (Hasle 1978) \\
\hline T. pseudonana & $2.3-5.5$ & Cosmopolitan \\
\hline T. punctigera & $40-186$ & Warm water region to temperate \\
\hline T. rotula & $8-55$ & Cosmopolitan \\
\hline T. tenera & $10-29$ & Cosmopolitan (Hasle and Fryxell 1977) \\
\hline T. tumida & 21-137 & Southern cold water region \\
\hline
\end{tabular}


Table 6: Multivariate correlation of Thalassiosira species composition with seven environmental factors (surface temperature, surface salinity, average daily PAR, DIP, DIN, Si and chlorophyll $a$ concentration) analyzed with BIOENV BEST using PRIMER v6.1.6 (PRIMER-E Ltd.).

\begin{tabular}{lll}
\hline $\begin{array}{l}\text { Number of } \\
\text { Variables }\end{array}$ & Correlation & Environmental Variables \\
\hline \hline 1 & 0.246 & Surface Temperature \\
2 & 0.232 & Surface Temperature, log (DIP) \\
3 & 0.224 & Surface Temperature, Average daily PAR, log (Si) \\
2 & 0.223 & Surface Temperature, Average daily PAR \\
3 & 0.223 & Surface Temperature, Average daily PAR, log (DIP) \\
2 & 0.219 & Surface Temperature, Surface Salinity \\
2 & 0.217 & Surface Temperature, log (Si) \\
3 & 0.208 & Surface Temperature, Surface Salinity, log (DIP) \\
4 & 0.207 & Surface Temperature, Average daily PAR, log (DIP), log (Si) \\
4 & 0.200 & Surface Temperature, Surface Salinity, Average daily PAR, log \\
& & (DIP)
\end{tabular}




\section{FIGURES}

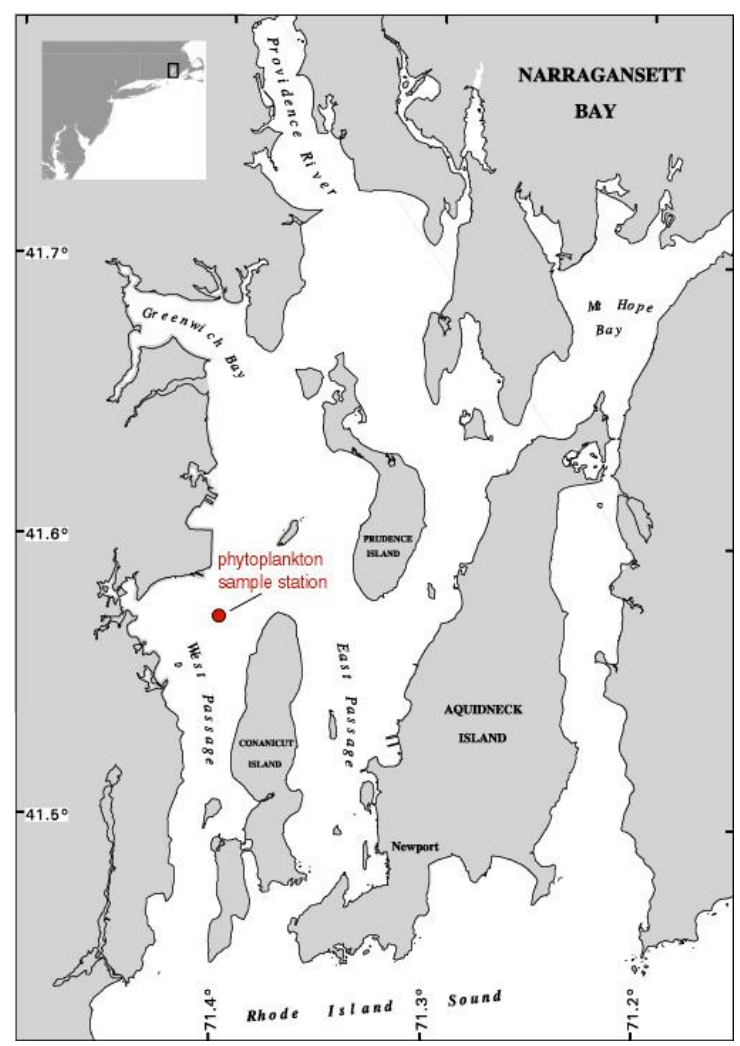

Figure 1: The geographic location of the sampling site for the Narragansett Bay Long Term Phytoplankton Time Series is located in the West Passage of Narragansett Bay, south of Quonset Point and east of Wickford Harbor. Water depth at this location is about $8 \mathrm{~m}$. 


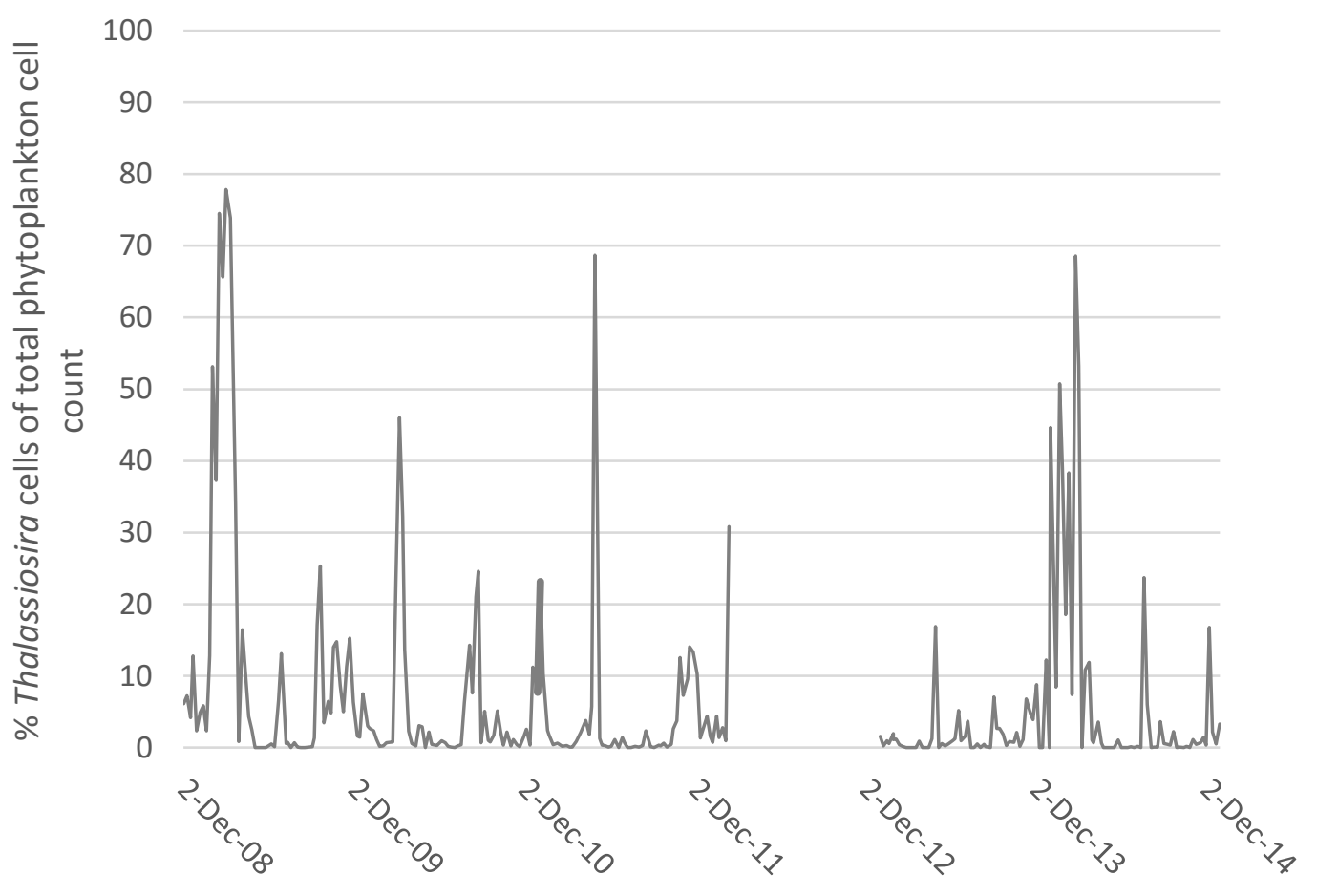

Figure 2: Relative abundance of Thalassiosira (percentage of the total phytoplankton cell counts) was calculated from LM cell counts of weekly surface phytoplankton samples from the Long Term Phytoplankton Time Series from December 2008 December 2014. Thalassiosira relative cell abundance varies from $0 \%$ to over $75 \%$ of the total phytoplankton community in Narragansett Bay and peaks in abundance vary seasonally and annually. 


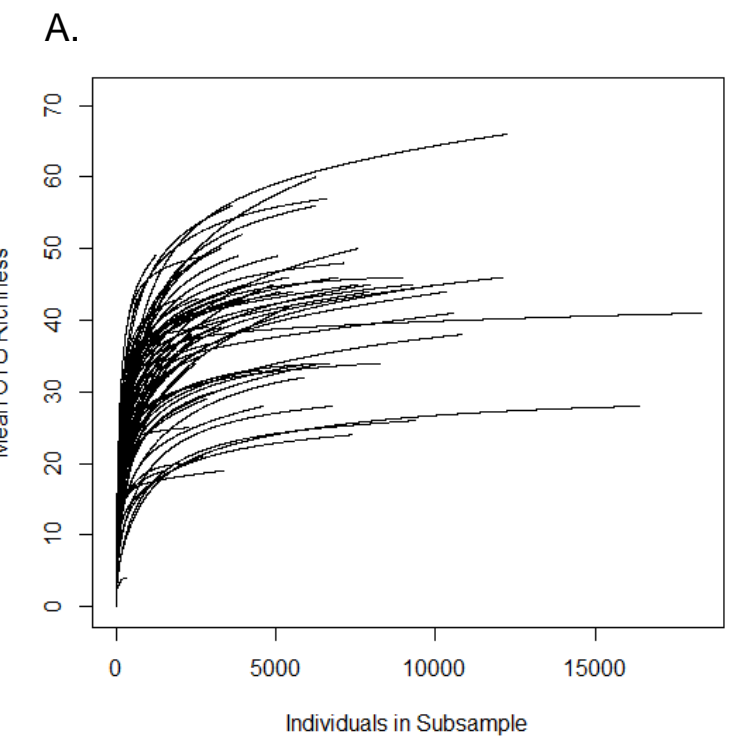

B.

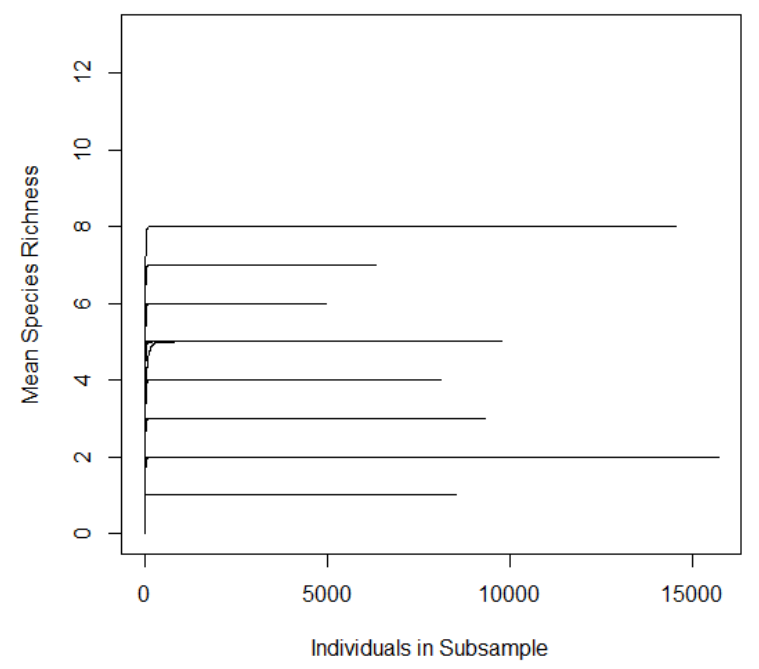

Figure 3: Rarefaction curves of operational taxon unit (OTU) richness (A) and species richness (B) for each of the 82 field sample sequence libraries. Figure A gives all OTUs generated in this study whereas Figure B is only showing only Thalassiosira species richness. The difference in figures is due to multiple OTUs corresponding to one species and the fact that the primers used in the study amplified all diatoms and raphidophytes in the samples, not just Thalassiosira species. 


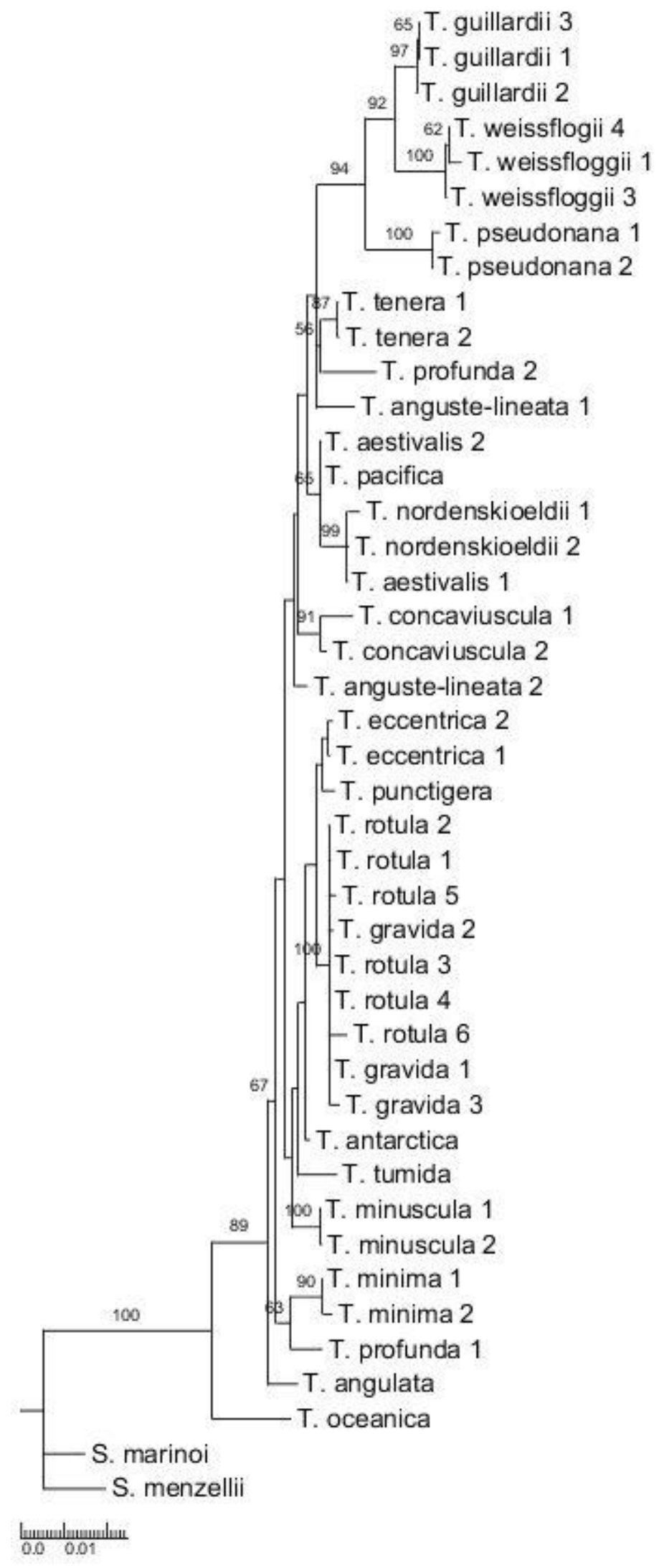

Figure 4: A maximum likelihood tree of a $1552 \mathrm{bp}$ fragment of Thalassiosira 18s sequences was constructed with Paup* 4.0 b10 (Swofford 2003). Numbers following species correspond to records in Table 2. Two Skeletonema species were used as an outgroup. Sequences were downloaded from GenBank and trimmed to the amplicon region used in this study. Bootstrap values (>50) are given at the nodes. Genetic distance in substitutions per site is provided by the scale bar at the bottom. Asterisks denote reference sequences recovered from field HTS results. 


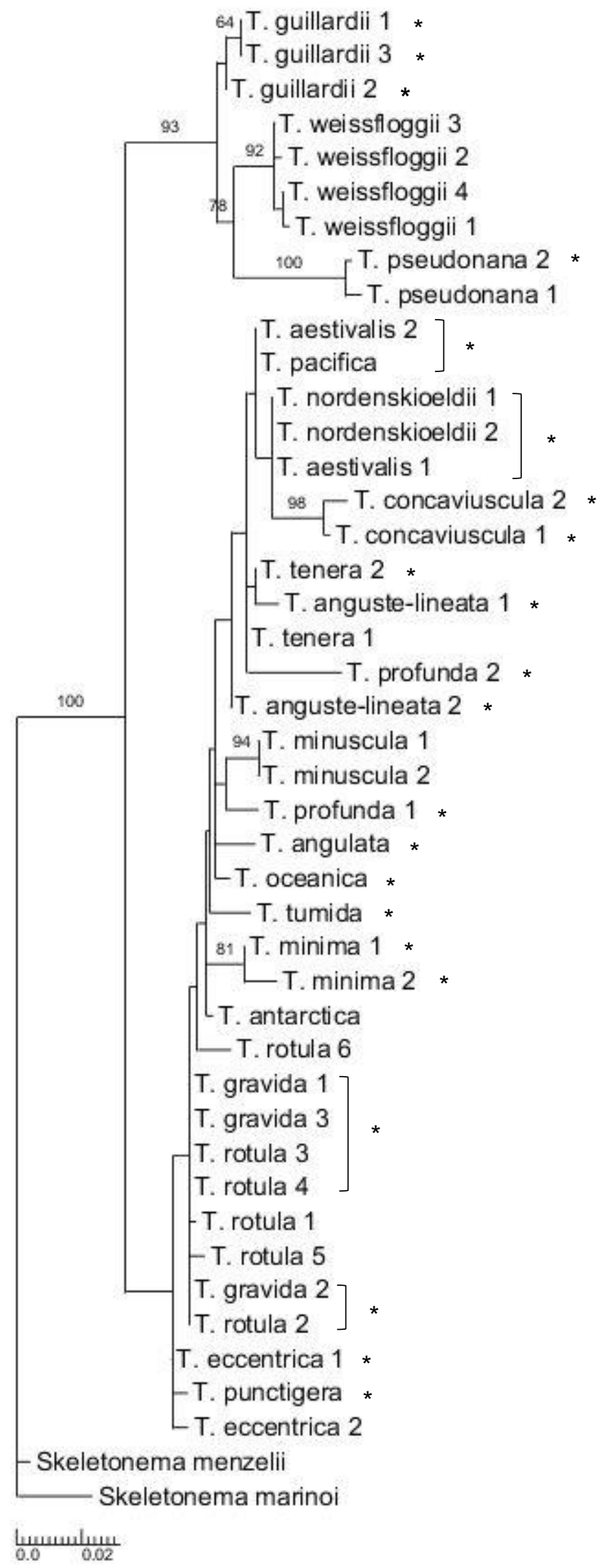

Figure 5: A maximum

likelihood tree of Thalassiosira 18S V4 sequences included in the curated reference database was constructed with Paup* 4.0 b10 (Swofford 2003). Numbers following species names correspond to records in Table 2. Two Skeletonema species were used as an outgroup.

Sequences were downloaded from GenBank and trimmed to the amplicon region used in this study. Bootstrap values ( $>50)$ are given at the nodes. Genetic distance in substitutions per site is provided by the scale bar at the bottom. Asterisks denote reference sequences recovered from field HTS results. Brackets with asterisks denote groups of sequences from different species that are indistinguishable at this locus. 
Mock Community 1

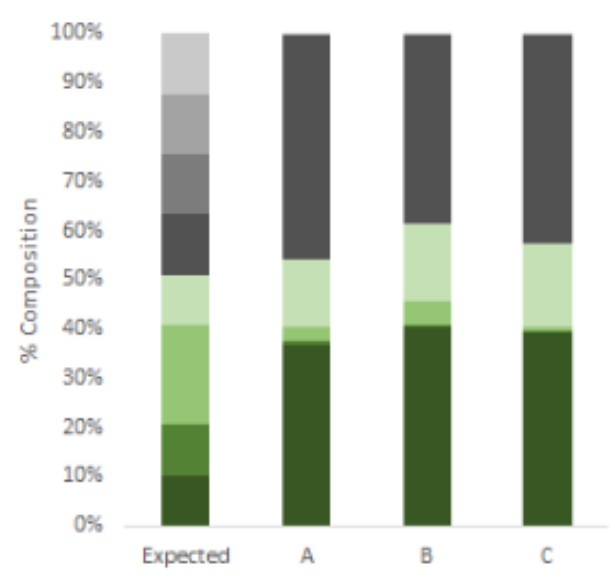

Mock Community 3

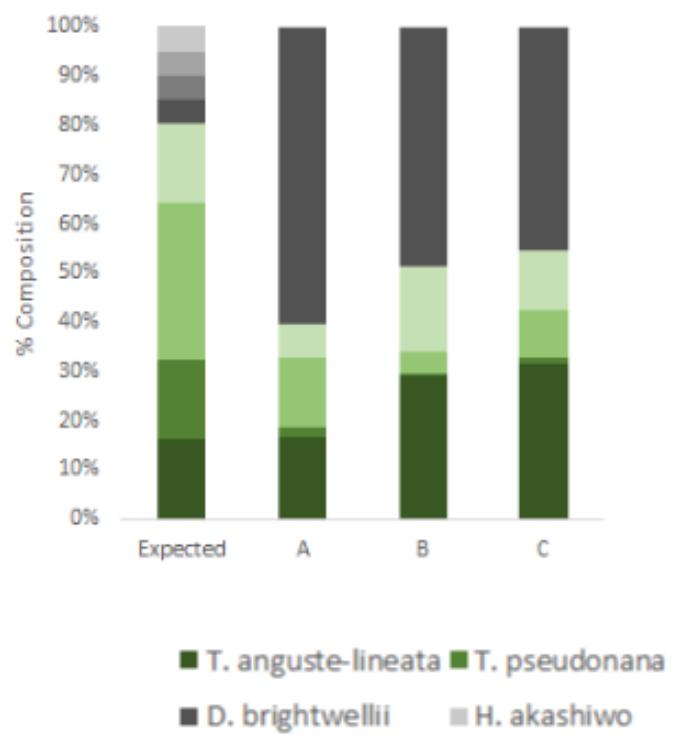

Mock Community 2

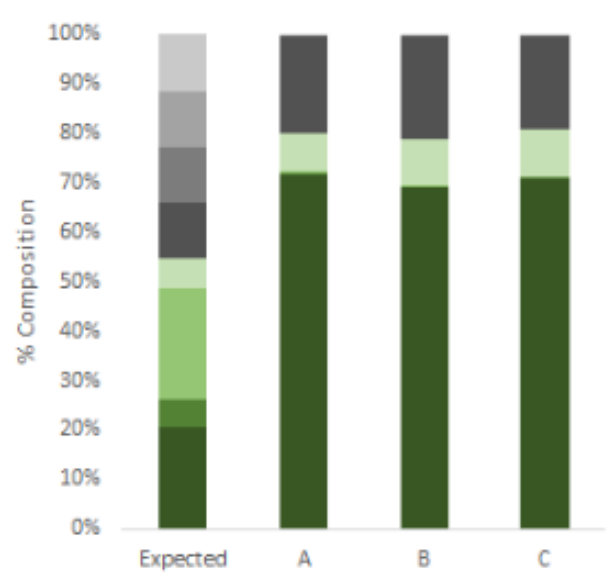

Mock Community 4

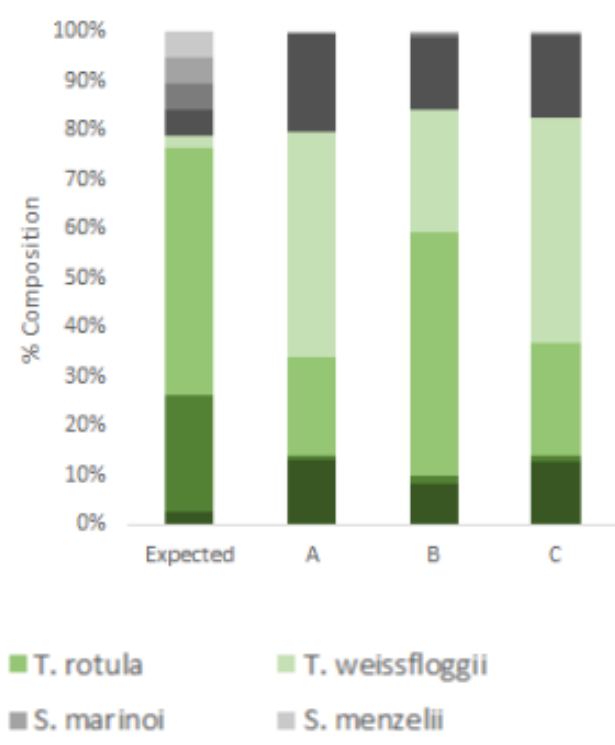

Figure 6: Expected and high-throughput sequence results for all four mock community experiments are shown as \% composition. Expected community composition from cell counts of each species is given in the leftmost column of each graph. Triplicate extraction sequence results for each mock community are shown as A, B and C in each graph. Observed mock community sequence data is significantly different than the expected composition ( $\chi$ square goodness-of-fit test, $\mathrm{p}<0.001$ ). Within all four of the triplicate mock communities $(\mathrm{A}, \mathrm{B}, \mathrm{C})$, composition did not vary significantly (ANOVA, $\mathrm{p}>0.05$ ). 

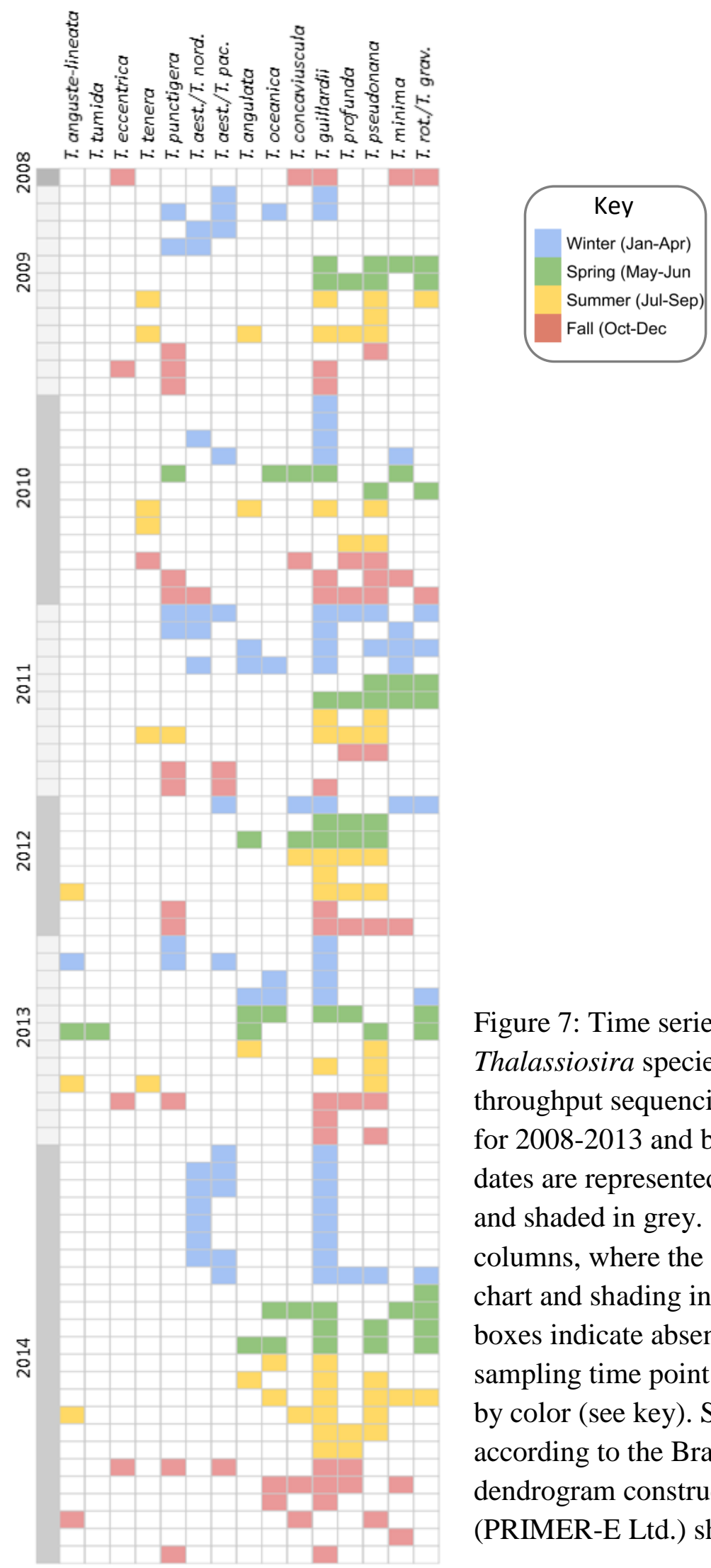

Figure 7: Time series occurrence of 15 Thalassiosira species detected by high throughput sequencing. Samples are monthly for 2008-2013 and bi-weekly for 2014. Sample dates are represented in rows. Years are labeled and shaded in grey. Species are given in columns, where the label is at the top of the chart and shading indicates presence. White boxes indicate absence of that species at that sampling time point. Seasons are represented by color (see key). Species in are arranged according to the Bray Curtis Similarity dendrogram constructed in PRIMER v6.1.6 (PRIMER-E Ltd.) shown in Figure 8. 


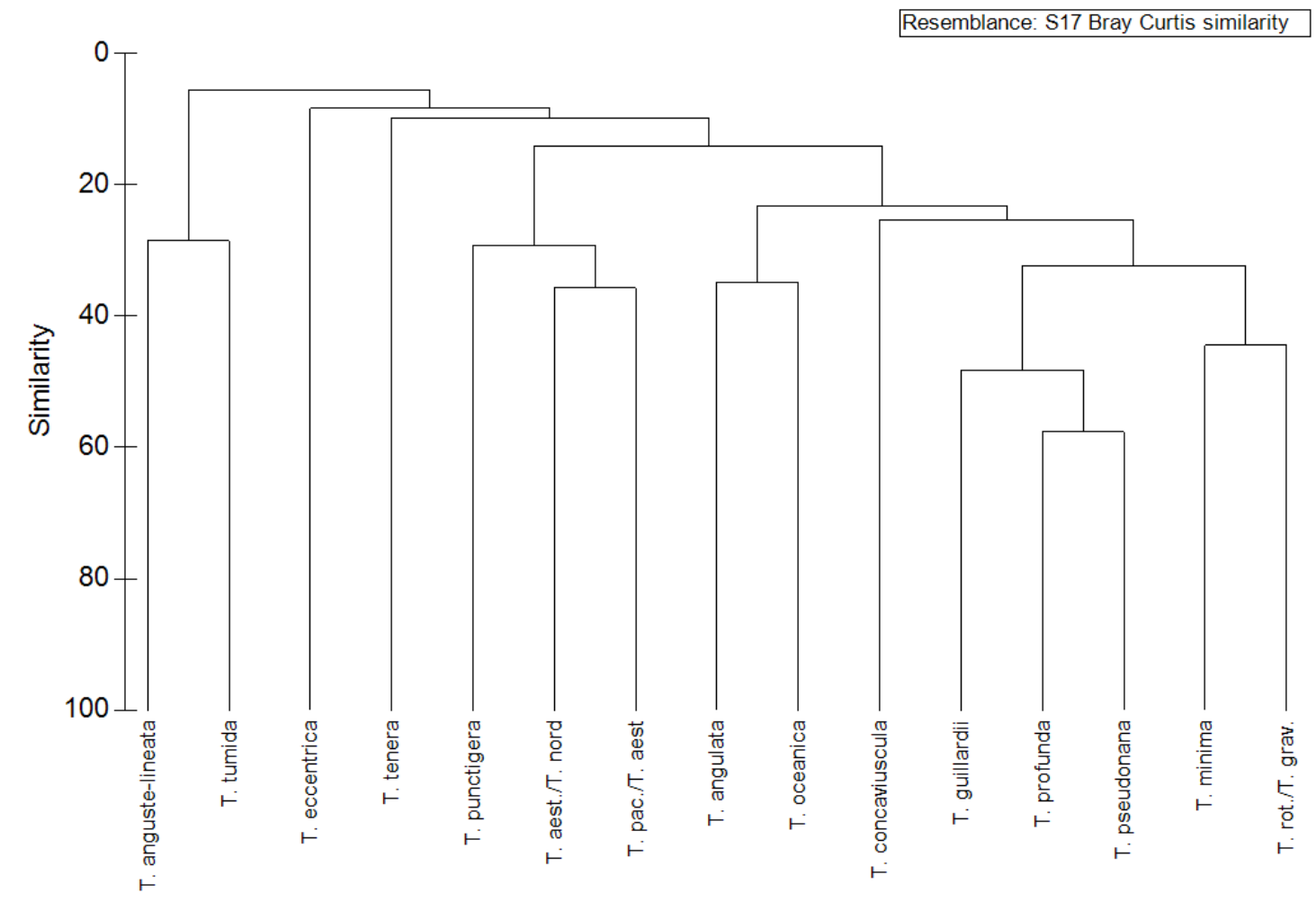

Figure 8: A Bray-Curtis similarity dendrogram is given for species composition constructed in PRIMER v6.1.6 (PRIMER-E Ltd.), indicating which species are likely to co-occur. Similarity is displayed in the y-axis of the dendrogram, from 0-100, where 100 indicates complete similarity and 0 indicates no similarity. Species names are abbreviated as follows: T. aest./nord. $=$ T. nordenskioeldii/T. aestivalis OTU; T. pac./aest. $=T$. pacifica/T. aestivalis OTU; T. rot./grav. $=T$. rotula/T. gravida OTU. 


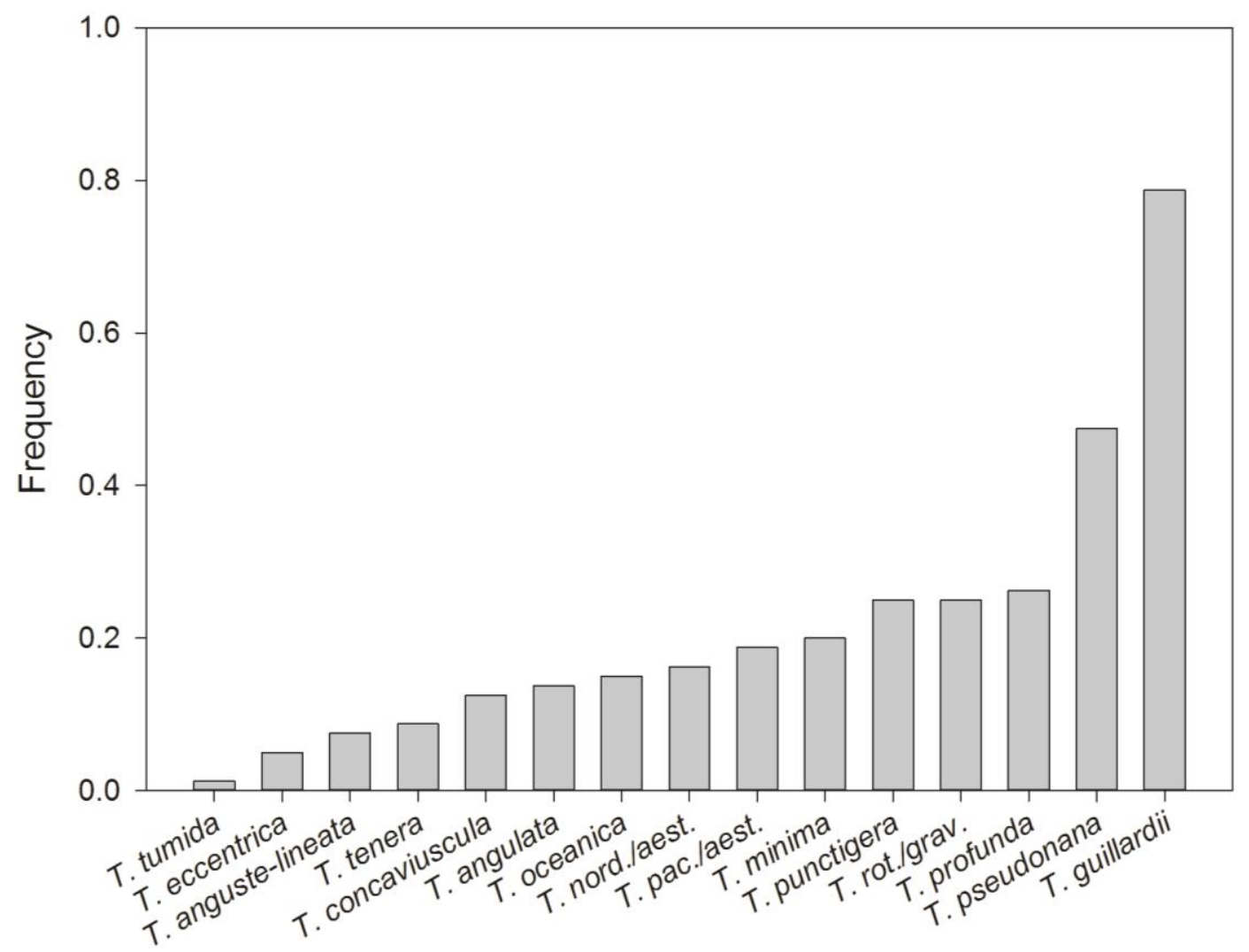

Figure 9: The frequency of occurrence in field samples of each species identified in the HTS results. Ten species have a frequency of $<0.2$ and two species have a frequency $>0.4$. Species names are abbreviated as follows: T. nord./aest. $=T$. nordenskioeldii/T. aestivalis OTU; T. pac./aest. $=$ T. pacifica/T. aestivalis OTU; T. $\operatorname{rot} / \mathrm{T}$. grav. $=T$. rotula $/ T$. gravida $\mathrm{OTU}$. 


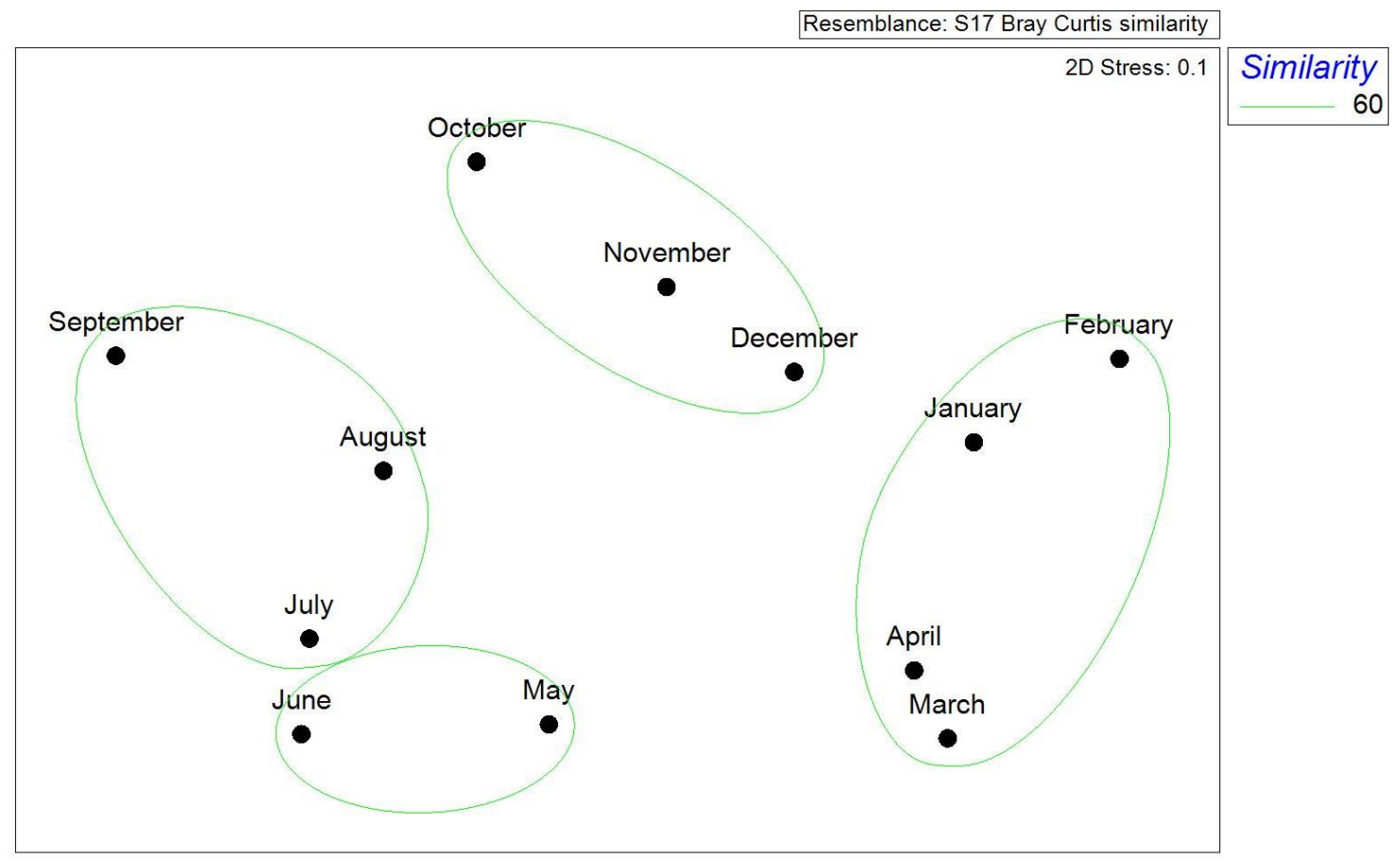

Figure 10: Multi-Dimensional Scaling plot (MDS) based on Bray-Curtis similarity of monthly averaged field sample presence/absence data averaged and normalized by sampling effort. Green rings denote $60 \%$ Bray-Curtis similarity. Four seasonal groups are apparent at the $60 \%$ similarity level: winter (January-April), spring (May-June), summer (July-September), fall (October-December). 
Similarity
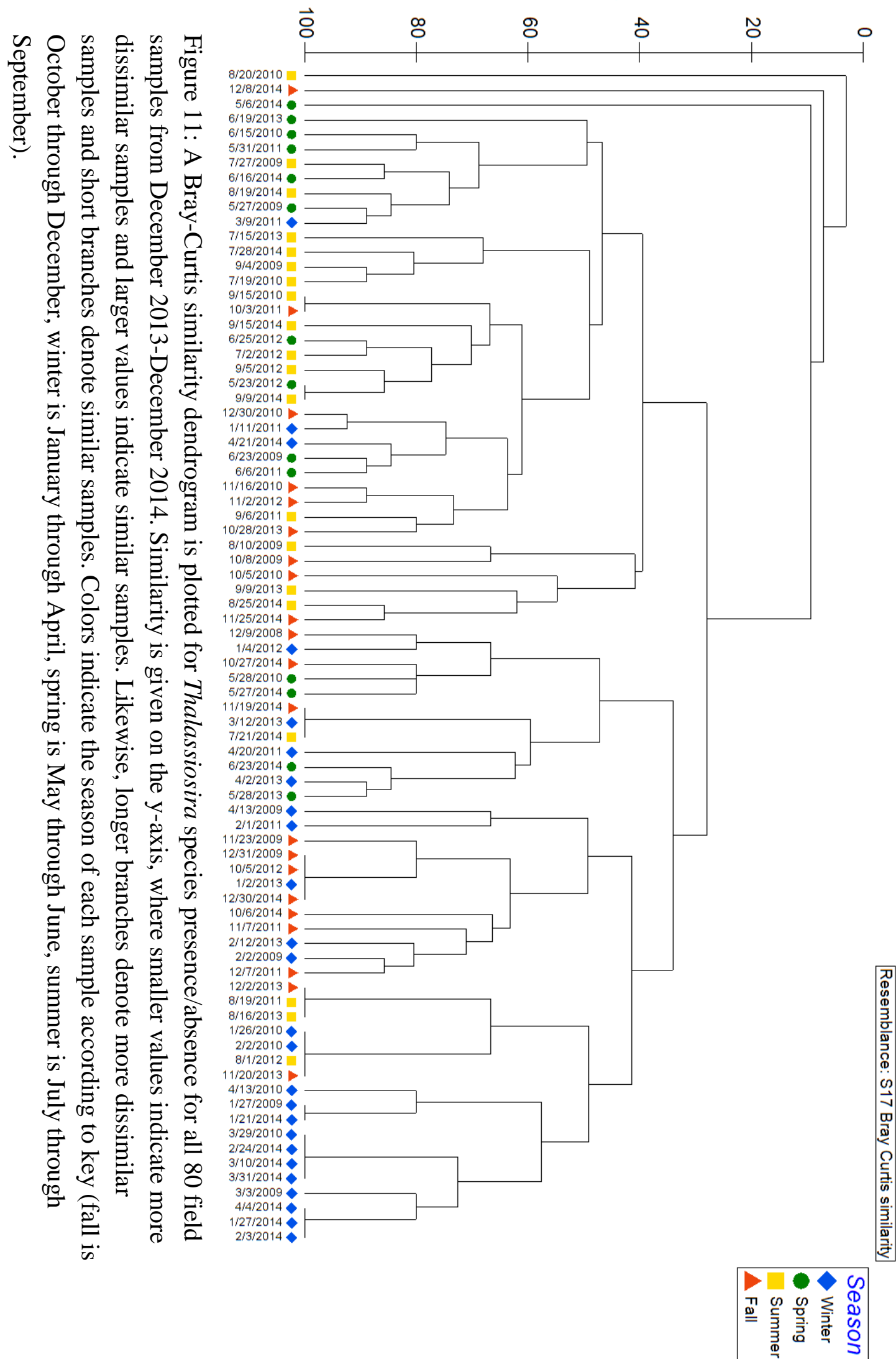


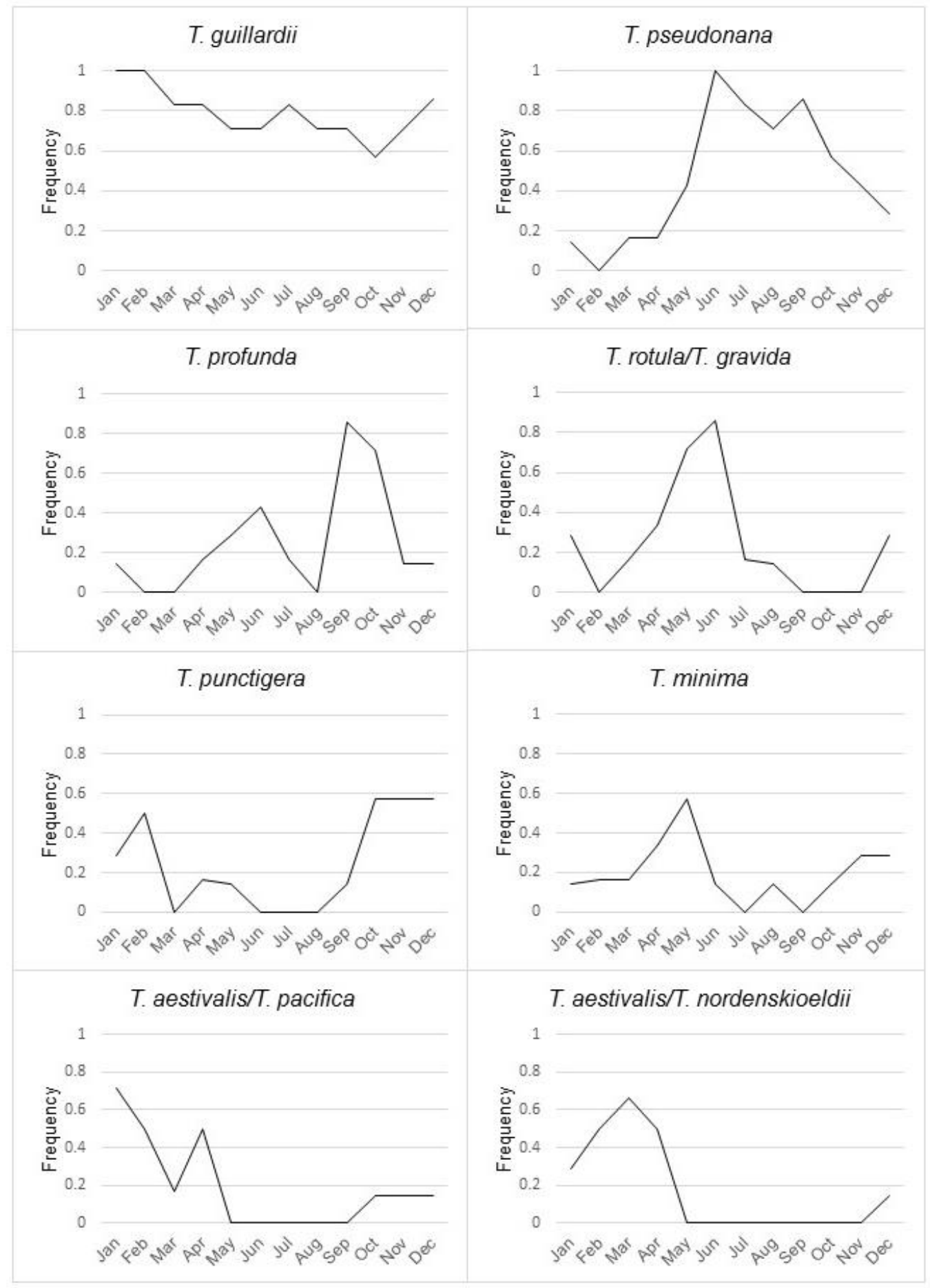

Figure 12: Occurrence frequency by month is presented for eight most frequent taxa in the HTS results as labeled in each panel. Number of years each individual taxa was present in each month was summed and divided by number of years sampled over the 6 year study period. All months were sampled 7 times each, with the exception of February, March and July, which were each sample 6 times each. 


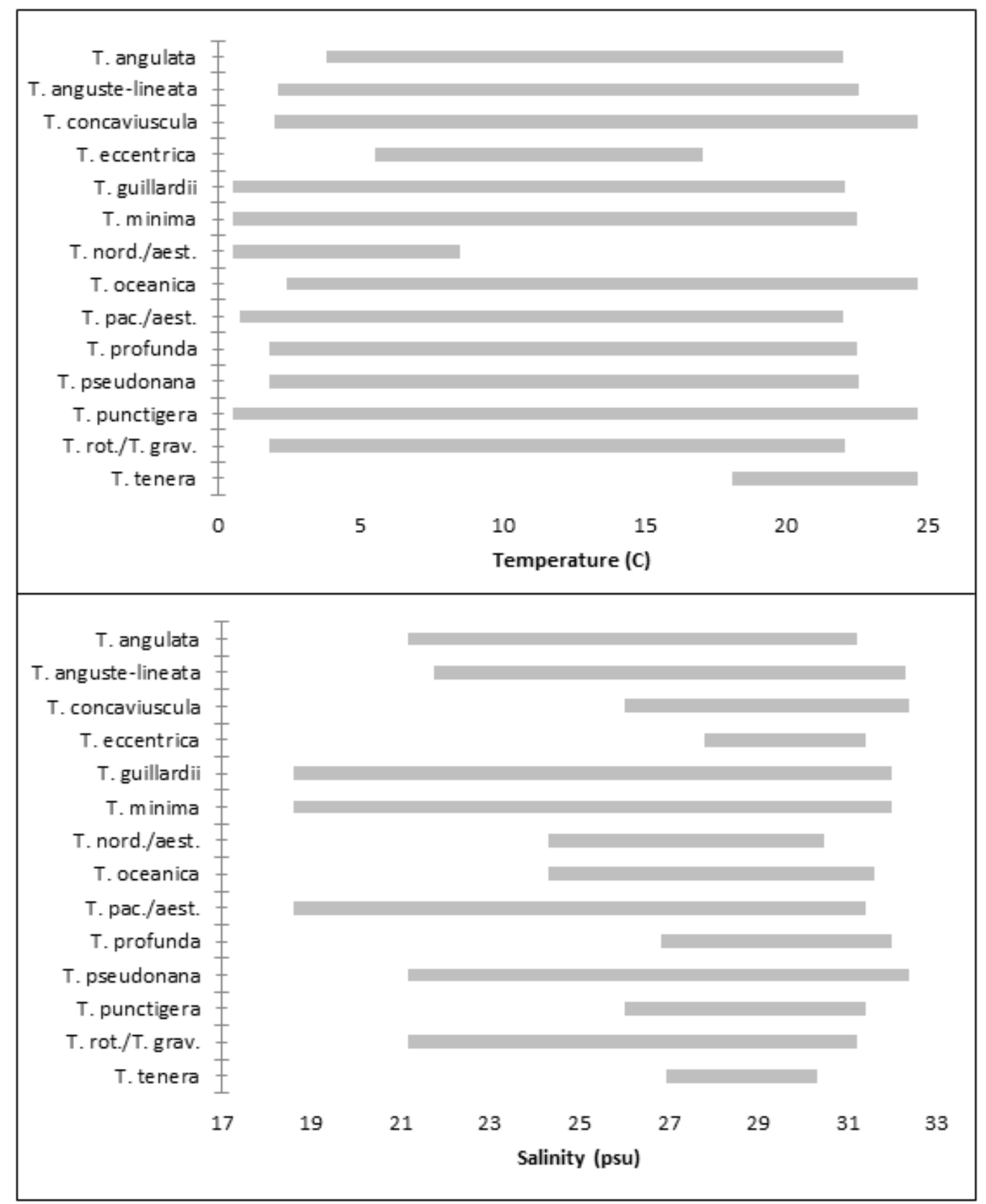

Figure 13: Observed temperature ranges (top panel) and salinity ranges (bottom panel) for fourteen of the Thalassiosira species recovered from the HTS data. The range for T. tenera is omitted since that species was only observed in one sample and therefore, does not have enough data for a range. Species names are abbreviated as follows: T. nord./aest. $=T$. nordenskioeldii/T. aestivalis OTU; T. pac./aest. $=T$. pacifica/T . aestivalis OTU; T. rot/T. grav. $=T$. rotula/T. gravida $\mathrm{OTU}$. 


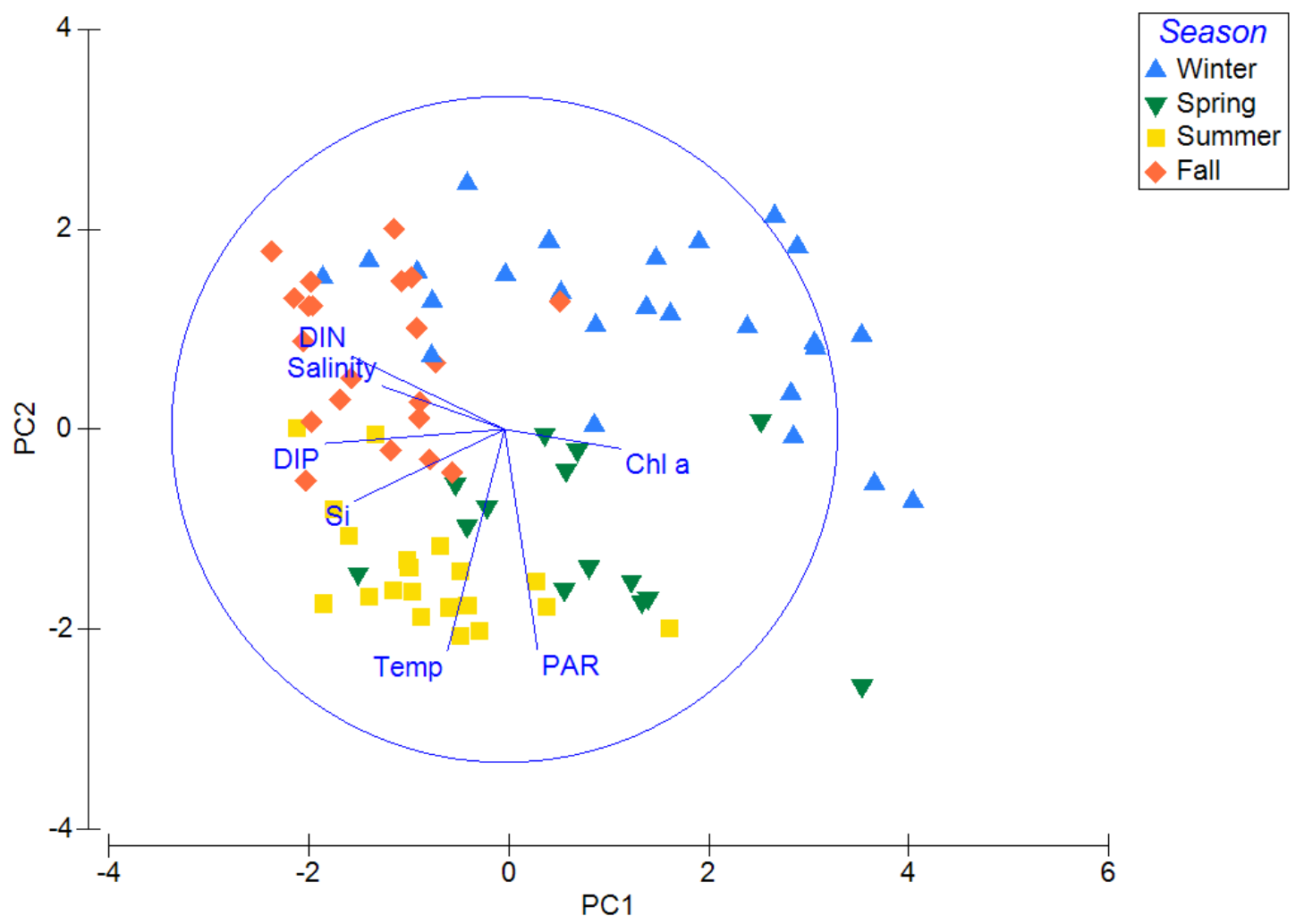

Figure 14: Principal components analysis of environmental data associated with each sample date for this study. Environmental variables included are surface temperature $\left({ }^{\circ} \mathrm{C}\right)$, surface salinity (ppt), surface chlorophyll $a(\mu / \mathrm{L})$, average daily PAR (mmol $/ \mathrm{m} 2)$, DIN $(\mu \mathrm{M})$, DIP $(\mu \mathrm{M})$, and $\operatorname{Si}(\mu \mathrm{M})$. Values for salinity, chlorophyll $a$, DIN, DIP, and Si were log transformed. Colors indicate the season of each sample (winter is January through April, spring is May through June, summer is July through September, fall is October through December). Surface temperature and average daily PAR contribute to PC2, separating winter samples from summer samples. PC1 explains $40.1 \%$ of the variance in these environmental parameters while PC1 and PC2 together explain $65.4 \%$ of the variance in the environmental parameters plotted here. 

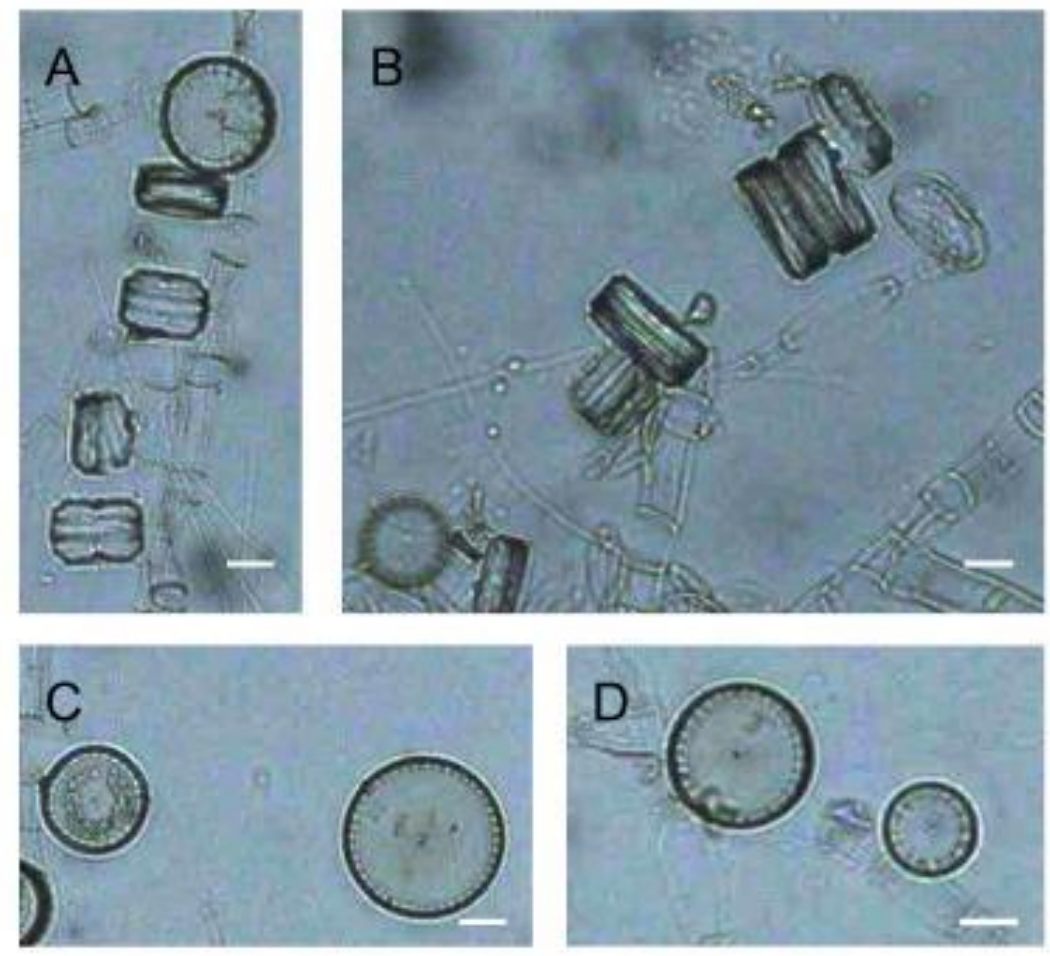

Figure 15: Thalassiosira spp. images from preserved slides of a sample collected on January 11, 2011. Thalassiosira nordenskioeldii was present in the LM cell counts from this sample and both T. aestivalis/T. nordenskioeldii and T. pacifica/T. aestivalis sequences were present in HTS results. All images taken at 200x. Scale bars (white) in lower right corners are $10 \mu \mathrm{m}$. A. Cells in this image are likely T. nordenskioeldii. Hexagonal shaped cells indicate T. nordenskioeldii or T. aestivalis. Slight depressions on the valve face are visible in girdle view cell, indicative of $T$. nordenskioeldii. B. Valve faces in girdle view cells may be concave, as in T. nordenskioeldii. C and D. A single central process is visible in these valve view cells, which appears in $T$. aestivalis, T. nordenskioeldii and T. pacifica. Several marginal processes are seen around the diameter of all cells. Closer marginal process spacing, as in the right cell in image $\mathrm{C}$, is indicative of $T$. aestivalis or $T$. pacifica. 


\section{APPENDICES}

Appendix 1: Dates for 80 field sampling dates in Narragansett Bay from December 2008 through December 2014 are given with the total phytoplankton abundance and Thalassiosira genus abundance for that day as quantified by light microscopy cell counts. Blanks in abundance columns indicate dates that were sequenced but for which no abundance data is available. Monthly samples were chosen for 2008-2013, with the exceptions of July 2011 and February-April 2012, when samples were not collected. Bi-weekly samples were sequenced for 2014.

\begin{tabular}{lll}
\hline & $\begin{array}{l}\text { Total Phytoplankton } \\
\text { Abundance } \\
\text { (cells/liter) }\end{array}$ & $\begin{array}{l}\text { Thalassiosira } \\
\text { Abundance } \\
\text { (cells/liter) }\end{array}$ \\
\hline \hline Date & 1866000 & 135000 \\
$12 / 9 / 2008$ & 31000 \\
$2 / 2 / 2009$ & 242000 & 110000 \\
$3 / 3 / 2009$ & 207000 & 717000 \\
$4 / 13 / 2009$ & 521000 & 533000 \\
$5 / 27 / 2009$ & 1153000 & 0 \\
$6 / 23 / 2009$ & 4680000 & 306000 \\
$7 / 27 / 2009$ & 10784000 & 70000 \\
$8 / 10 / 2009$ & 25849000 & 0 \\
$9 / 4 / 2009$ & 17383000 & 16000 \\
$10 / 8 / 2009$ & 541000 & 35000 \\
$11 / 23 / 2009$ & 438000 & 67000 \\
$12 / 31 / 2009$ & 728000 & 22000 \\
$1 / 26 / 2010$ & 19612000 & 34000 \\
$2 / 2 / 2010$ & 10633000 & 23000 \\
$3 / 29 / 2010$ & 6085000 & 140000 \\
$4 / 13 / 2010$ & 49346000 & 112000 \\
$5 / 28 / 2010$ & 4942000 & 13000 \\
$6 / 15 / 2010$ & 12709000 & 84000 \\
$7 / 19 / 2010$ & 18144000 & 75000 \\
$8 / 20 / 2010$ & 8015000 & 1683000 \\
$9 / 15 / 2010$ & 599000 & 6000 \\
$10 / 5 / 2010$ & 2101000 & 107000 \\
$11 / 16 / 2010$ & 1474000 & 6000 \\
$12 / 30 / 2010$ & 1179000 & 91000 \\
$1 / 11 / 2011$ & 4991000 & 514000 \\
$2 / 1 / 2011$ & 3539000 & 14000 \\
$3 / 9 / 2011$ & 2840000 & 2000 \\
$4 / 20 / 2011$ & 14207667 & 262000 \\
$5 / 31 / 2011$ & 4361000 & 2000 \\
& & \\
\hline
\end{tabular}




\begin{tabular}{|c|c|c|}
\hline $6 / 6 / 2011$ & 19456000 & 29000 \\
\hline 8/19/2011 & 1861000 & 43000 \\
\hline 9/6/2011 & 3590000 & 0 \\
\hline $10 / 3 / 2011$ & 2460000 & 2000 \\
\hline $11 / 7 / 2011$ & 454000 & 33000 \\
\hline $12 / 7 / 2011$ & 165000 & 17000 \\
\hline $1 / 4 / 2012$ & 699000 & 11000 \\
\hline \multicolumn{3}{|l|}{$5 / 23 / 2012$} \\
\hline \multicolumn{3}{|l|}{$6 / 25 / 2012$} \\
\hline \multicolumn{3}{|l|}{$7 / 2 / 2012$} \\
\hline \multicolumn{3}{|l|}{ 8/1/2012 } \\
\hline \multicolumn{3}{|l|}{ 9/5/2012 } \\
\hline \multicolumn{3}{|l|}{$10 / 5 / 2012$} \\
\hline \multicolumn{3}{|l|}{$11 / 2 / 2012$} \\
\hline \multicolumn{3}{|l|}{$1 / 2 / 2013$} \\
\hline $1 / 2 / 2013$ & 45200 & 700 \\
\hline $2 / 12 / 2013$ & 8272800 & 31000 \\
\hline $3 / 12 / 2013$ & 1157000 & 0 \\
\hline $4 / 2 / 2013$ & 807800 & 0 \\
\hline $5 / 28 / 2013$ & 478000 & 2500 \\
\hline $6 / 19 / 2013$ & 15745200 & 815000 \\
\hline $7 / 15 / 2013$ & 48604100 & 0 \\
\hline $8 / 16 / 2013$ & 2769200 & 4000 \\
\hline 9/9/2013 & 5512100 & 147000 \\
\hline $10 / 28 / 2013$ & 199700 & 400 \\
\hline $11 / 20 / 2013$ & 851900 & 40000 \\
\hline $12 / 2 / 2013$ & 809000 & 71000 \\
\hline $1 / 21 / 2014$ & 987700 & 501000 \\
\hline $1 / 27 / 2014$ & 1239500 & 479000 \\
\hline $2 / 3 / 2014$ & 944000 & 175000 \\
\hline $2 / 24 / 2014$ & 889300 & 610000 \\
\hline $3 / 10 / 2014$ & 409500 & 0 \\
\hline $3 / 31 / 2014$ & 4297900 & 45000 \\
\hline $4 / 4 / 2014$ & 12428800 & 84000 \\
\hline $4 / 21 / 2014$ & 6082100 & 39000 \\
\hline $5 / 6 / 2014$ & 746000 & 0 \\
\hline $5 / 27 / 2014$ & 93800 & 1000 \\
\hline $6 / 16 / 2014$ & 6100267 & 0 \\
\hline $6 / 23 / 2014$ & 19872200 & 21000 \\
\hline $7 / 21 / 2014$ & 4286100 & 18000 \\
\hline $7 / 28 / 2014$ & 13656400 & 819000 \\
\hline $8 / 19 / 2014$ & 10642500 & 4000 \\
\hline $8 / 25 / 2014$ & 5256900 & 819000 \\
\hline
\end{tabular}




$\begin{array}{lll}9 / 9 / 2014 & 446000 & 4000 \\ 9 / 15 / 2014 & 900000 & 224000 \\ 10 / 6 / 2014 & 2469000 & 4000 \\ 10 / 27 / 2014 & 565000 & 0 \\ 11 / 19 / 2014 & 435000 & 3000 \\ 11 / 25 / 2014 & 288000 & 4000 \\ 12 / 8 / 2014 & 192100 & 32200 \\ 12 / 30 / 2014 & 609000 & 20000\end{array}$


Appendix 2: Dates for 80 field sampling dates in Narragansett Bay from December 2008 through December 2014 are given with the Thalassiosira species abundance for that day quantified by light microscopy cell counts. Blanks in abundance columns indicate dates that were sequenced but for which no abundance data is available. Monthly samples were chosen for 2008-2013, with the exceptions of July 2011 and February-April 2012, when samples were not collected. Bi-weekly samples were sequenced for 2014.

\begin{tabular}{|c|c|c|c|c|}
\hline & $\begin{array}{c}T . \\
\text { nordenskioeldii }\end{array}$ & $\begin{array}{c}T . \\
\text { punctigera }\end{array}$ & $\begin{array}{l}\text { T. rotulal } \\
\text { gravida }\end{array}$ & $\begin{array}{c}T . \\
\text { spp. }\end{array}$ \\
\hline $12 / 9 / 2008$ & 0 & 0 & 0 & 500 \\
\hline $1 / 27 / 2009$ & 0 & 0 & 0 & 0 \\
\hline $2 / 2 / 2009$ & 69000 & 0 & 0 & 0 \\
\hline $3 / 3 / 2009$ & 717000 & 0 & 0 & 0 \\
\hline 4/13/2009 & 533000 & 0 & 0 & 0 \\
\hline $5 / 27 / 2009$ & 0 & 0 & 0 & 0 \\
\hline $6 / 23 / 2009$ & 0 & 0 & 0 & 0 \\
\hline $7 / 27 / 2009$ & 0 & 0 & 0 & 0 \\
\hline $8 / 10 / 2009$ & 0 & 0 & 0 & 0 \\
\hline 9/4/2009 & 0 & 0 & 0 & 0 \\
\hline $10 / 8 / 2009$ & 0 & 3000 & 0 & 0 \\
\hline $11 / 23 / 2009$ & 0 & 0 & 0 & 0 \\
\hline $12 / 31 / 2009$ & 0 & 1000 & 0 & 0 \\
\hline $1 / 26 / 2010$ & 8000 & 0 & 0 & 0 \\
\hline $2 / 2 / 2010$ & 0 & 0 & 0 & 0 \\
\hline $3 / 29 / 2010$ & 126000 & 0 & 0 & 0 \\
\hline $4 / 13 / 2010$ & 102000 & 0 & 0 & 0 \\
\hline $5 / 28 / 2010$ & 0 & 0 & 0 & 0 \\
\hline $6 / 15 / 2010$ & 0 & 0 & 0 & 0 \\
\hline $7 / 19 / 2010$ & 0 & 0 & 0 & 0 \\
\hline $8 / 20 / 2010$ & 0 & 0 & 0 & 0 \\
\hline $9 / 15 / 2010$ & 0 & 0 & 0 & 0 \\
\hline $10 / 5 / 2010$ & 0 & 0 & 0 & 0 \\
\hline $11 / 16 / 2010$ & 0 & 0 & 0 & 0 \\
\hline $12 / 30 / 2010$ & 40000 & 1000 & 0 & 48000 \\
\hline $1 / 11 / 2011$ & 492000 & 0 & 0 & 15000 \\
\hline $2 / 1 / 2011$ & 12000 & 0 & 0 & 0 \\
\hline 3/9/2011 & 0 & 0 & 0 & 0 \\
\hline 4/20/2011 & 262000 & 0 & 0 & 0 \\
\hline $5 / 31 / 2011$ & 0 & 0 & 0 & 0 \\
\hline 6/6/2011 & 0 & 0 & 0 & 22000 \\
\hline 8/19/2011 & 0 & 0 & 0 & 0 \\
\hline 9/6/2011 & 0 & 0 & 0 & 0 \\
\hline
\end{tabular}




\begin{tabular}{|c|c|c|c|c|}
\hline $10 / 3 / 2011$ & 0 & 0 & 0 & 0 \\
\hline $11 / 7 / 2011$ & 0 & 8000 & 0 & 0 \\
\hline $12 / 7 / 2011$ & 0 & 3000 & 0 & 0 \\
\hline $1 / 4 / 2012$ & 0 & 0 & 0 & 0 \\
\hline \multicolumn{5}{|l|}{$5 / 23 / 2012$} \\
\hline \multicolumn{5}{|l|}{$6 / 25 / 2012$} \\
\hline \multicolumn{5}{|l|}{ 7/2/2012 } \\
\hline \multicolumn{5}{|l|}{$8 / 1 / 2012$} \\
\hline \multicolumn{5}{|l|}{$9 / 5 / 2012$} \\
\hline \multicolumn{5}{|l|}{$10 / 5 / 2012$} \\
\hline \multicolumn{5}{|l|}{$11 / 2 / 2012$} \\
\hline \multicolumn{5}{|l|}{$1 / 2 / 2013$} \\
\hline $1 / 2 / 2013$ & 0 & 0 & 0 & 0 \\
\hline $2 / 12 / 2013$ & 0 & 0 & 0 & 0 \\
\hline $3 / 12 / 2013$ & 0 & 0 & 0 & 0 \\
\hline $4 / 2 / 2013$ & 0 & 0 & 0 & 0 \\
\hline $5 / 28 / 2013$ & 0 & 0 & 0 & 0 \\
\hline $6 / 19 / 2013$ & 0 & 0 & 0 & 0 \\
\hline $7 / 15 / 2013$ & 0 & 0 & 0 & 0 \\
\hline $8 / 16 / 2013$ & 0 & 0 & 0 & 0 \\
\hline 9/9/2013 & 0 & 0 & 0 & 29000 \\
\hline $10 / 28 / 2013$ & 0 & 0 & 0 & 0 \\
\hline $11 / 20 / 2013$ & 0 & 0 & 0 & 10000 \\
\hline $12 / 2 / 2013$ & 0 & 0 & 0 & 71000 \\
\hline $1 / 21 / 2014$ & 0 & 0 & 0 & 60000 \\
\hline $1 / 27 / 2014$ & 0 & 0 & 0 & 95000 \\
\hline 2/3/2014 & 0 & 0 & 0 & 27000 \\
\hline $2 / 24 / 2014$ & 0 & 0 & 0 & 0 \\
\hline $3 / 10 / 2014$ & 0 & 0 & 0 & 0 \\
\hline $3 / 31 / 2014$ & 0 & 0 & 0 & 0 \\
\hline $4 / 4 / 2014$ & 0 & 0 & 0 & 4000 \\
\hline $4 / 21 / 2014$ & 39000 & 0 & 0 & 0 \\
\hline $5 / 6 / 2014$ & 0 & 0 & 0 & 0 \\
\hline $5 / 27 / 2014$ & 0 & 0 & 0 & 0 \\
\hline $6 / 16 / 2014$ & 0 & 0 & 0 & 0 \\
\hline $6 / 23 / 2014$ & 0 & 0 & 0 & 0 \\
\hline $7 / 21 / 2014$ & 0 & 0 & 0 & 18000 \\
\hline $7 / 28 / 2014$ & 0 & 0 & 0 & 0 \\
\hline 8/19/2014 & 0 & 0 & 0 & 0 \\
\hline $8 / 25 / 2014$ & 0 & 0 & 0 & 0 \\
\hline 9/9/2014 & 0 & 0 & 0 & 0 \\
\hline $9 / 15 / 2014$ & 0 & 0 & 0 & 0 \\
\hline $10 / 6 / 2014$ & 0 & 0 & 0 & 0 \\
\hline
\end{tabular}


$10 / 27 / 2014$

$11 / 19 / 2014$

$11 / 25 / 2014$

$12 / 8 / 2014$

$12 / 30 / 2014$

$\begin{array}{lllr}0 & 0 & 0 & 0 \\ 0 & 0 & 0 & 0 \\ 0 & 0 & 0 & 0 \\ 0 & 0 & 0 & 200 \\ 0 & 0 & 0 & 0\end{array}$


Appendix 3: Total sequence pairs are given for each sample and the $\%$ of reads surviving after merging and filtering is given. Dates are given to identify the 80 field samples. FST $=$ Field Sample Triplicate $; \mathrm{MCT}=$ Mock Community Triplicate $; \mathrm{MC1}-$ MC4 = Mock Communities 1-4.

\begin{tabular}{|c|c|c|c|}
\hline \multirow[b]{2}{*}{ Date/Sample } & \multicolumn{3}{|c|}{ \# Sequences } \\
\hline & $\begin{array}{c}\text { \# Raw } \\
\text { Sequence Pairs }\end{array}$ & $\begin{array}{c}\text { Post } \\
\text { Processing } \\
\end{array}$ & $\begin{array}{c}\% \\
\text { Surviving } \\
\end{array}$ \\
\hline $12 / 9 / 2008$ & 255177 & 14521 & 5.69 \\
\hline $1 / 27 / 2009$ & 145180 & 8422 & 5.80 \\
\hline $2 / 2 / 2009$ & 140346 & 6036 & 4.30 \\
\hline $3 / 3 / 2009$ & 114711 & 3056 & 2.66 \\
\hline 4/13/2009 & 196912 & 10008 & 5.08 \\
\hline $5 / 27 / 2009$ & 221158 & 7013 & 3.17 \\
\hline $6 / 23 / 2009$ & 134667 & 5860 & 4.35 \\
\hline $7 / 27 / 2009$ & 182865 & 5431 & 2.97 \\
\hline $8 / 10 / 2009$ & 120095 & 5502 & 4.58 \\
\hline $9 / 4 / 2009$ & 134498 & 5764 & 4.29 \\
\hline $10 / 8 / 2009$ & 136573 & 6158 & 4.51 \\
\hline $11 / 23 / 2009$ & 162485 & 4468 & 2.75 \\
\hline $12 / 31 / 2009$ & 129098 & 5985 & 4.64 \\
\hline $1 / 26 / 2010$ & 140674 & 10428 & 7.41 \\
\hline $2 / 2 / 2010$ & 101792 & 4980 & 4.89 \\
\hline $3 / 29 / 2010$ & 202189 & 8155 & 4.03 \\
\hline $4 / 13 / 2010$ & 146527 & 5081 & 3.47 \\
\hline $5 / 28 / 2010$ & 148210 & 4271 & 2.88 \\
\hline $6 / 15 / 2010$ & 127744 & 3704 & 2.90 \\
\hline $7 / 19 / 2010$ & 72164 & 776 & 1.08 \\
\hline $8 / 20 / 2010$ & 281234 & 7651 & 2.72 \\
\hline $9 / 15 / 2010$ & 137015 & 3447 & 2.52 \\
\hline $10 / 5 / 2010$ & 138851 & 3217 & 2.32 \\
\hline $11 / 16 / 2010$ & 172452 & 3012 & 1.75 \\
\hline $12 / 30 / 2010$ & 179573 & 13896 & 7.74 \\
\hline $1 / 11 / 2011$ & 245228 & 24069 & 9.81 \\
\hline $2 / 1 / 2011$ & 243232 & 19842 & 8.16 \\
\hline $3 / 9 / 2011$ & 153565 & 4380 & 2.85 \\
\hline $4 / 20 / 2011$ & 196164 & 2067 & 1.05 \\
\hline $5 / 31 / 2011$ & 197398 & 16015 & 8.11 \\
\hline $6 / 6 / 2011$ & 103276 & 172 & 0.17 \\
\hline $8 / 19 / 2011$ & 175560 & 20527 & 11.69 \\
\hline 9/6/2011 & 161465 & 15073 & 9.34 \\
\hline $10 / 3 / 2011$ & 205795 & 25320 & 12.30 \\
\hline $11 / 7 / 2011$ & 212989 & 20778 & 9.76 \\
\hline $12 / 7 / 2011$ & 116734 & 7143 & 6.12 \\
\hline $1 / 4 / 2012$ & 200879 & 12378 & 6.16 \\
\hline $5 / 23 / 2012$ & 244447 & 21447 & 8.77 \\
\hline $6 / 25 / 2012$ & 181029 & 15415 & 8.52 \\
\hline $7 / 2 / 2012$ & 180062 & 23239 & 12.91 \\
\hline $8 / 1 / 2012$ & 195191 & 13812 & 7.08 \\
\hline $9 / 5 / 2012$ & 181376 & 16162 & 8.91 \\
\hline $10 / 5 / 2012$ & 198987 & 10935 & 5.50 \\
\hline 11/2/2012 & 163263 & 5171 & 3.17 \\
\hline
\end{tabular}




\begin{tabular}{|c|c|c|c|}
\hline $1 / 2 / 2013$ & 222317 & 13312 & 5.99 \\
\hline $2 / 12 / 2013$ & 168643 & 14651 & 8.69 \\
\hline $3 / 12 / 2013$ & 155320 & 12097 & 7.79 \\
\hline $4 / 2 / 2013$ & 216061 & 11010 & 5.10 \\
\hline $5 / 28 / 2013$ & 58448 & 4659 & 7.97 \\
\hline $6 / 19 / 2013$ & 142475 & 13823 & 9.70 \\
\hline $7 / 15 / 2013$ & 178433 & 19408 & 10.88 \\
\hline $8 / 16 / 2013$ & 128707 & 3578 & 2.78 \\
\hline 9/9/2013 & 131126 & 10081 & 7.69 \\
\hline $10 / 28 / 2013$ & 122585 & 11334 & 9.25 \\
\hline $11 / 20 / 2013$ & 122134 & 11088 & 9.08 \\
\hline $12 / 2 / 2013$ & 133863 & 10807 & 8.07 \\
\hline $1 / 21 / 2014$ & 214763 & 13339 & 6.21 \\
\hline $1 / 27 / 2014$ & 127159 & 1530 & 1.20 \\
\hline $2 / 3 / 2014$ & 170470 & 7509 & 4.40 \\
\hline $2 / 24 / 2014$ & 166239 & 7360 & 4.43 \\
\hline $3 / 10 / 2014$ & 193472 & 17337 & 8.96 \\
\hline $3 / 31 / 2014$ & 166761 & 6754 & 4.05 \\
\hline $4 / 4 / 2014$ & 202389 & 13906 & 6.87 \\
\hline $4 / 21 / 2014$ & 173732 & 12044 & 6.93 \\
\hline $5 / 6 / 2014$ & 171535 & 18372 & 10.71 \\
\hline $5 / 27 / 2014$ & 183364 & 15956 & 8.70 \\
\hline $6 / 16 / 2014$ & 161328 & 18090 & 11.21 \\
\hline $6 / 23 / 2014$ & 141669 & 11282 & 7.96 \\
\hline $7 / 21 / 2014$ & 186566 & 15510 & 8.31 \\
\hline $7 / 28 / 2014$ & 241130 & 26869 & 11.14 \\
\hline $8 / 19 / 2014$ & 186100 & 14919 & 8.02 \\
\hline $8 / 25 / 2014$ & 249490 & 23405 & 9.38 \\
\hline $9 / 9 / 2014$ & 160043 & 9164 & 5.73 \\
\hline $9 / 15 / 2014$ & 137876 & 9772 & 7.09 \\
\hline $10 / 6 / 2014$ & 115319 & 5202 & 4.51 \\
\hline $10 / 27 / 2014$ & 111218 & 3564 & 3.20 \\
\hline $11 / 19 / 2014$ & 144845 & 11978 & 8.27 \\
\hline $11 / 25 / 2014$ & 173187 & 13450 & 7.77 \\
\hline $12 / 8 / 2014$ & 124275 & 10316 & 8.30 \\
\hline $12 / 30 / 2014$ & 123401 & 5284 & 4.28 \\
\hline FST & 156349 & 10262 & 6.56 \\
\hline FST & 165973 & 10418 & 6.28 \\
\hline Мст & 133939 & 9274 & 6.92 \\
\hline MCT & 123498 & 6735 & 5.45 \\
\hline MC1 & 220995 & 25357 & 11.47 \\
\hline $\mathrm{MC1}$ & 212757 & 22583 & 10.61 \\
\hline MC1 & 185309 & 21057 & 11.36 \\
\hline MC2 & 204383 & 19944 & 9.76 \\
\hline MC2 & 204192 & 11763 & 5.76 \\
\hline MC2 & 164451 & 7029 & 4.27 \\
\hline MC3 & 188280 & 3121 & 1.66 \\
\hline MC3 & 116071 & 3771 & 3.25 \\
\hline MC3 & 206657 & 15049 & 7.28 \\
\hline MC4 & 199419 & 14554 & 7.30 \\
\hline MC4 & 191195 & 12149 & 6.35 \\
\hline MC4 & 198349 & 12769 & 6.44 \\
\hline
\end{tabular}


Appendix 4: Presence/absence data of all 15 Thalassiosira OTUs for all 80 field sample dates as obtained from 18S V4 sequencing. X's indicate presence. Species names are abbreviated as follows: $T$. aest./nord $=T$. aestivalis/T. nordenskioeldii; $T$. angu $=T$. angulata $;$. ang-lin. = T. anguste-lineata $;$. con. = T. concaviuscula $;$. ecc. $=$ T. eccentrica; $T$. guil. $=T$. guillardii, T. min. $=T$. minima; $T$. oce.$=T$. oceanica; $T$. pac./aest. $=T$. pacifica/T. aestivalis; $T$. prof. $=T$. profunda $;$. pseu. $=T$. pseudonana $;$ T. punc. $=T$. punctigera $;$ T. rot./grav. $=T$. rotula/T. gravida $;$. ten. $=$ T. tenera; T. tum. = T. tumida .

\begin{tabular}{|c|c|c|c|c|c|c|c|c|c|c|c|c|c|c|}
\hline & 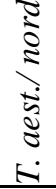 & 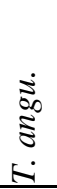 & 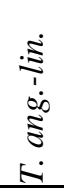 & 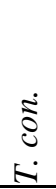 & 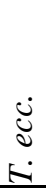 & 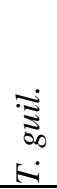 & $\begin{array}{r}\stackrel{\Xi}{\Xi} \\
\text { ה }\end{array}$ & 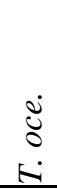 & 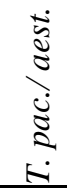 & $\begin{array}{l}\overrightarrow{0} \\
\frac{2}{2} \\
-i\end{array}$ & 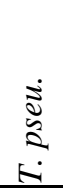 & $\begin{array}{r}\dot{\Xi} \\
\stackrel{\Xi}{\Xi} \\
ن\end{array}$ & 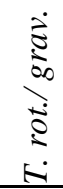 & 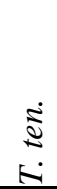 \\
\hline $12 / 9 / 2008$ & & & & $\mathrm{X}$ & $\mathrm{X}$ & $X$ & $\mathrm{X}$ & & & & & & $\mathrm{X}$ & \\
\hline $1 / 27 / 2009$ & & & & & & $X$ & $X$ & & $\mathrm{X}$ & & & & & \\
\hline 2/2/2009 & & & & & & $X$ & $X$ & $X$ & $\mathrm{X}$ & & & $X$ & & \\
\hline $3 / 3 / 2009$ & $X$ & & & & & & $X$ & & $\mathrm{X}$ & & & & & \\
\hline 4/13/2009 & $\mathrm{X}$ & & & & & & $\mathrm{X}$ & & & & & $\mathrm{X}$ & & \\
\hline 5/27/2009 & & & & & & $\mathrm{X}$ & $X$ & & & & $\mathrm{X}$ & & $\mathrm{X}$ & \\
\hline 6/23/2009 & & & & & & $X$ & $X$ & & & $\mathrm{X}$ & $\mathrm{X}$ & & $\mathrm{X}$ & \\
\hline $7 / 27 / 2009$ & & & & & & $\mathrm{X}$ & $X$ & & & & $\mathrm{X}$ & & $X$ & $\mathrm{X}$ \\
\hline $8 / 10 / 2009$ & & & & & & & & & & & $X$ & & & \\
\hline $9 / 4 / 2009$ & & $\mathrm{X}$ & & & & $X$ & & & & $\mathrm{X}$ & $\mathrm{X}$ & & & $\mathrm{X}$ \\
\hline $10 / 8 / 2009$ & & & & & & & $\mathrm{X}$ & & & & $\mathrm{X}$ & $X$ & & \\
\hline $11 / 23 / 2009$ & & & & & $\mathrm{X}$ & $X$ & $X$ & & & & & $\mathrm{X}$ & & \\
\hline $12 / 31 / 2009$ & & & & & & $X$ & $\mathrm{X}$ & & & & & $X$ & & \\
\hline $1 / 26 / 2010$ & & & & & & $X$ & $X$ & & & & & & & \\
\hline $2 / 2 / 2010$ & & & & & & $X$ & & & & & & & & \\
\hline $3 / 29 / 2010$ & $\mathrm{X}$ & & & & & $X$ & & & & & & & & \\
\hline $4 / 13 / 2010$ & & & & & & $X$ & $X$ & & $\mathrm{X}$ & & & & & \\
\hline $5 / 28 / 2010$ & & & & $X$ & & $X$ & $X$ & $X$ & & & & $X$ & & \\
\hline $6 / 15 / 2010$ & & & & & & & $X$ & & & & $X$ & & $X$ & \\
\hline $7 / 19 / 2010$ & & $\mathrm{X}$ & & & & $\mathrm{X}$ & & & & & $X$ & & & $\mathrm{X}$ \\
\hline $8 / 20 / 2010$ & & & & & & & & & & & & & & $X$ \\
\hline $9 / 15 / 2010$ & & & & & & & $X$ & & & $\mathrm{X}$ & $\mathrm{X}$ & & & \\
\hline $10 / 5 / 2010$ & & & & $X$ & & & & & & $X$ & $X$ & & & $\mathrm{X}$ \\
\hline $11 / 16 / 2010$ & & & & & & $X$ & $X$ & & & & $X$ & $\mathrm{X}$ & & \\
\hline $12 / 30 / 2010$ & $\mathrm{X}$ & & & & & $X$ & $\mathrm{X}$ & & & $\mathrm{X}$ & $X$ & $\mathrm{X}$ & $X$ & \\
\hline $1 / 11 / 2011$ & $\mathrm{X}$ & & & & & $X$ & $\mathrm{X}$ & & $X$ & $X$ & $\mathrm{X}$ & $X$ & $X$ & \\
\hline $2 / 1 / 2011$ & $\mathrm{X}$ & & & & & $X$ & $X$ & & & & & $X$ & & \\
\hline $3 / 9 / 2011$ & & $\mathrm{X}$ & & & & $X$ & $X$ & & & & $\mathrm{X}$ & & $X$ & \\
\hline $4 / 20 / 2011$ & $X$ & $X$ & & & & $X$ & & $X$ & & & & & & \\
\hline
\end{tabular}




\begin{tabular}{|c|c|c|c|c|c|c|c|c|c|c|c|c|c|c|}
\hline $5 / 31 / 2011$ & & & & & & & $\mathrm{X}$ & & & & $X$ & & $X$ & \\
\hline 6/6/2011 & & & & & & $X$ & $X$ & & & $X$ & $\mathrm{X}$ & & $X$ & \\
\hline $8 / 19 / 2011$ & & & & & & $\mathrm{X}$ & & & & & $X$ & & & \\
\hline 9/6/2011 & & & & & & $\mathrm{X}$ & & & & $\mathrm{X}$ & $\mathrm{X}$ & $\mathrm{X}$ & & $X$ \\
\hline $10 / 3 / 2011$ & & & & & & & $X$ & & & $X$ & $\mathrm{X}$ & & & \\
\hline $11 / 7 / 2011$ & & & & & & & & & $\mathrm{X}$ & & & $X$ & & \\
\hline $12 / 7 / 2011$ & & & & & & $X$ & $X$ & & $\mathrm{X}$ & & & $X$ & & \\
\hline $1 / 4 / 2012$ & & & & $X$ & & $\mathrm{X}$ & $\mathrm{X}$ & & $X$ & & & & $X$ & \\
\hline $5 / 23 / 2012$ & & & & & & $X$ & & & & $\mathrm{X}$ & $X$ & & & \\
\hline $6 / 25 / 2012$ & & $\mathrm{X}$ & & $\mathrm{X}$ & & $\mathrm{X}$ & & & & $X$ & $\mathrm{X}$ & & & \\
\hline 7/2/2012 & & & & $X$ & & $X$ & & & & $X$ & $\mathrm{X}$ & & & \\
\hline $8 / 1 / 2012$ & & & & & & $\mathrm{X}$ & & & & & & & & \\
\hline 9/5/2012 & & & $X$ & & & $X$ & $X$ & & & $X$ & $X$ & & & \\
\hline $10 / 5 / 2012$ & & & & & & $\mathrm{X}$ & $\mathrm{X}$ & & & & & $\mathrm{X}$ & & \\
\hline $11 / 2 / 2012$ & & & & & & $\mathrm{X}$ & $X$ & & & $X$ & $\mathrm{X}$ & $X$ & & \\
\hline $1 / 2 / 2013$ & & & & & & $\mathrm{X}$ & $X$ & & & & & $X$ & & \\
\hline $2 / 12 / 2013$ & & & $X$ & & & $\mathrm{X}$ & & & $X$ & & & $X$ & & \\
\hline $3 / 12 / 2013$ & & & & & & $\mathrm{X}$ & & $\mathrm{X}$ & & & & & & \\
\hline $4 / 2 / 2013$ & & $X$ & & & & $\mathrm{X}$ & & $X$ & & & & & $X$ & \\
\hline $5 / 28 / 2013$ & & $X$ & & & & $\mathrm{X}$ & & $\mathrm{X}$ & & $\mathrm{X}$ & & & $\mathrm{X}$ & \\
\hline $6 / 19 / 2013$ & & $X$ & $X$ & & & & & & & & $X$ & & $X$ & \\
\hline $7 / 15 / 2013$ & & $\mathrm{X}$ & & & & & & & & & $\mathrm{X}$ & & & \\
\hline $8 / 16 / 2013$ & & & & & & $X$ & & & & & $X$ & & & \\
\hline 9/9/2013 & & & $X$ & & & & $X$ & & & & $\mathrm{X}$ & & & $X$ \\
\hline $10 / 28 / 2013$ & & & & & $\mathrm{X}$ & $X$ & $\mathrm{X}$ & & & $\mathrm{X}$ & $X$ & $X$ & & \\
\hline $11 / 20 / 2013$ & & & & & & $X$ & $X$ & & & & & & & \\
\hline $12 / 2 / 2013$ & & & & & & $\mathrm{X}$ & $X$ & & & & $X$ & & & \\
\hline $1 / 21 / 2014$ & & & & & & $X$ & $X$ & & $\mathrm{X}$ & & & & & \\
\hline $1 / 27 / 2014$ & $X$ & & & & & $X$ & $X$ & & $X$ & & & & & \\
\hline 2/3/2014 & $X$ & & & & & $\mathrm{X}$ & & & $X$ & & & & & \\
\hline $2 / 24 / 2014$ & $X$ & & & & & $\mathrm{X}$ & & & & & & & & \\
\hline $3 / 10 / 2014$ & $X$ & & & & & $X$ & & & & & & & & \\
\hline $3 / 31 / 2014$ & $X$ & & & & & $X$ & $X$ & & & & & & & \\
\hline $4 / 4 / 2014$ & $X$ & & & & & $X$ & $X$ & & $X$ & & & & & \\
\hline $4 / 21 / 2014$ & & & & & & $X$ & & & $X$ & $X$ & $X$ & & $X$ & \\
\hline $5 / 6 / 2014$ & & & & & & & & & & & & & $\mathrm{X}$ & \\
\hline $5 / 27 / 2014$ & & & & X & & $X$ & $X$ & $\mathrm{X}$ & & & & & $X$ & \\
\hline $6 / 16 / 2014$ & & & & & & $X$ & $X$ & & & & $X$ & & $X$ & \\
\hline $6 / 23 / 2014$ & & $X$ & & & & $\mathrm{X}$ & & $X$ & & & $X$ & & $\mathrm{X}$ & \\
\hline $7 / 21 / 2014$ & & & & & & $X$ & $X$ & X & & & & & & \\
\hline $7 / 28 / 2014$ & & $\mathrm{X}$ & & & & $X$ & & & & & $X$ & & & \\
\hline $8 / 19 / 2014$ & & & & & & $X$ & X & $\mathrm{X}$ & & & $X$ & & $\mathrm{X}$ & \\
\hline $8 / 25 / 2014$ & & & $X$ & $\mathrm{X}$ & & $\mathrm{X}$ & & & & & $X$ & & & \\
\hline
\end{tabular}


9/9/2014

9/15/2014

$10 / 6 / 2014$

$10 / 27 / 2014$

$11 / 19 / 2014$

$11 / 25 / 2014$

$12 / 8 / 2014$

$12 / 30 / 2014$

\begin{tabular}{|c|c|c|c|c|c|c|}
\hline & $X$ & $X$ & & & $X$ & X \\
\hline & $X$ & $X$ & & & $X$ & \\
\hline$X$ & $X$ & $X$ & & $X$ & $X$ & \\
\hline$X$ & $X$ & $X$ & $X$ & & $X$ & \\
\hline & $X$ & $X$ & $X$ & & & \\
\hline$X$ & & & & & & $X$ \\
\hline & & $X$ & & & & \\
\hline & $X$ & $X$ & & & & \\
\hline
\end{tabular}




\section{BIBLIOGRAPHY}

Alexander H, BD Jenkins, TA Rynearson, ST Dyhrman (2015) Metatranscriptome analyses indicate resource partitioning between diatoms in the field.

Proceedings of the National Academy of Sciences 112 (17). doi:10.1073/pnas.1421993112.

Alverson AJ, RK Jansen, EC Theriot (2007) Bridging the Rubicon: phylogenetic analysis reveals repeated colonizations of marine and fresh waters by thalassiosiroid diatoms. Mol. Phylogenet. Evol. 45(1): 193-210.

Alverson, AJ (2008) Molecular Systematics and the Diatom Species. Protist 159(3): 339-353.

Alverson AJ (2013) Timing marine-freshwater transitions in the diatom order Thalassiosirales. Paleobiology 40(1): 91-101.

Amaral-Zettler LA, EA McCliment, HW Ducklow, SM Huse (2007) A Method for Studying Protistan Diversity Using Massively Parallel Sequencing of V9 Hypervariable Regions of Small-Subunit Ribosomal RNA Genes. PLoS ONE 4, e6372.

Armbrust EV, HM Galindo (2001) Rapid evolution of a sexual reproduction gene in centric diatoms of the genus Thalassiosira. Appl Environ Microbiol 67(8): 3501-3513.

Armbrust EV, JA Berges, C Bowler, BR Green, D Martinez, NH Putnam, S Zhou, AE Allen, KE Apt, M Bechner, MA Brzezinski, BK Chaal, A Chiovitti, AK Davis, MS Demarest, JC Detter, T Glavina, D Goodstein, MZ Hadi, U Hellsten, M Hildebrand, BD Jenkins, J Jurka, VV Kapitonov, N Kroger, WWY Lau, TW Lane, FW Larimer, JC Lippmeier, S Lucas, M Medina, A Montsant, M Obornik, MS Parker, B Palenik, GJ Pazour, PM Richardson, TA Rynearson, MA Saito, DC Schwartz, K Thamatrakoln, K Valentin, A Vardi, FP Wilkerson, DS Rokhsar (2004) The Genome of the Diatom Thalassiosira pseudonana: Ecology, Evolution and Metabolism. Science 306(5693): 79-86. doi:10.1126/science.1101156.

Balzano S, D Marie, P Gourvil, D Vaulot (2012) Composition of the summer photosynthetic pico and nanoplankton communities in the Beaufort Sea assessed by T-RFLP and sequences of the 18S rRNA gene from flow cytometry sorted samples. ISME J. 6(8): 1480-1498.

Belcher JH, EMF Swale (1986) Notes on some small Thalassiosira species (Bacillariophyceae) from the plankton of the lower Thames and other British Estuaries (identified by transmission electron microscopy). British Phycological Journal, 21(2): 139-145. DOI: 10.1080/00071618600650161 
Bolger AM, M Lohse, B Usadel (2014). Trimmomatic: A flexible trimmer for Illumina Sequence Data. Bioinformatics, btu170.

Borkman D (2009) Gulf Stream position and winter NAO as drivers of long-term variations in the bloom phenology of the diatom Skeletonema costatum "species-complex" in Narragansett Bay, RI, USA. J. Plankton Res. 31(11): 1407-1425. doi:10.1093/plankt/fbp072.

Borkman DG, T Smayda (2009) Multidecadal (1959-1997) changes in Skeletonema abundance and seasonal bloom patterns in Narragansett Bay, Rhode Island, USA. Journal of Sea Research 61(1-2):84-94.

Bushnell B. BBMap. Sourceforge.net/projects/bbmap/

Canesi KL, TA Rynearson (in press) Temporal variation of Skeletonema community composition from a long-term time series in Narragansett Bay identified using high-throughput sequencing. Marine Ecology Progress Series.

Caporaso JG, J Kuczynski, J Stombaugh, K Bittinger, FD Bushman, EK Costello, R Knight (2010) QIIME allows analysis of high-throughput community sequencing data. Nature Methods 7(5): 335-336. doi:10.1038/nmeth.f.303

Chappell PD, LP Whitney, TL Haddock, S Menden-Deuer, EG Roy, ML Wells, BD Jenkins (2013) Thalassiosira spp. Community composition shifts in response to chemical and physical forcing in the northeast Pacific Ocean. Frontiers in Microbiology 4(273):1-14.

Cleary AC, EG Durbin, TA Rynearson (2012) Krill feeding on sediment in the Gulf of Maine (North Atlantic). Mar. Ecol. Prog. Ser. 455: 157-172.

Damste JS, G Muyzer, B Abbas, SW Rampen, G Masse, WG Allard, ST Belt, JM Robert, SJ Rowland, JM Moldowan, SM Barbanti, FJ Fago, P Denisevich, J Dahl, LA Trindade, S Schouten (2004) The rise of rhizosolenid diatoms. Science 304(5670): 584-587.

Darriba D, GL Taboada, R Doalla, D Posada (2012) jModelTest 2: more models, new heuristics and parallel computing. Nature Methods 9(8): 772.

Deason EE and TJ Smayda (1981) Ctenophore-zooplankton-phytoplankton interactions in Narragansett Bay, Rhode Island, USA, during 1972-1977. Journal of Plankton Research 4(2): 203-217.

De La Rocha C, A Terbrueggen, C Voelker, S Hohn (2010) Response to and recovery from nitrogen and silicon starvation in Thalassiosira weissflogii: growth rates, nutrient uptake and C, Si and N content per cell. Marine Ecology Progress Series 412: 57-68. 
Edgar RC (2010) Search and clustering orders of magnitude faster than BLAST. Bioinformatics 26(19): 2460-2461. doi: 10.1093/bioinformatics/btq461

Edgar RC, BJ Haas, JC Clemente, C Quince, R Knight (2011) UCHIME improves sensitivity and speed of chimera detection. Bioinformatics 27(16): 2194-2200. doi: 10.1093/bioinformatics/btr381.

Eren ME, HG Morrison, PJ Lescault, J Reveillaud, JH Vineis, ML Sogin (2015) Minimum entropy decomposition: Unsupervised oligotyping for sensitive partitioning of high-throughput marker gene sequences. The ISME Journal 9: 968-979. doi: 10.1038/ismej2014.195.

Field CB, MJ Behrenfeld, JT Randerson, P Falkowski (1998) Primary production of the biosphere: Integrating terrestrial and oceanic components. Science 281(5374):237-240.

Gast RJ, MR Dennett, DA Caron (2004) Characterization of Protistan Assemblages in the Ross Sea, Antarctica, by Denaturing Gradient Gel Electrophoresis. Applied and Environmental Microbiology 70(4): 2028-2037.

Guindon S and Gascuel O (2003). A simple, fast and accurate method to estimate large phylogenies by maximum-likelihood. Systematic Biology 52: 696-704.

Hamsher SE, KM Evans, DG Mann, A Poulickova, GW Saunders (2011) Barcoding Diatoms: Exploring Alternatives to COI-5P. Protist 162: 405-522.

Hamsher SE, MM LeGresley, JL Martin, GW Saunders (2013) A Comparison of Morphological and Molecular-Based Surveys to Estimate the Species Richness of Chaetoceros and Thalassiosira (Bacillariophyta), in the Bay of Fundy. PLoS ONE 8(10): e73521. doi:10.1371/journal.pone.0073521.

Harris ASD, LK Medlin, J Lewis, KJ Jones (1995) Thalassiosira species (Bacillariophyceae) from a Scottish sea-loch. European Journal of Phycology 30: 117-131.

Harvey EL, S Menden-Deuer, TA Rynearson (2015) Persistent Intra-Specific Variation in Genetic and Behavioral Traits in the Raphidophyte, Heterosigma akashiwo. Front. Microbiol. 6: 1277.

Hasle GR (1978) Some freshwater and brackish water species of the diatom genus Thalassiosira Cleve. Phycologia: September 1978 17(3): 263-292.

Hasle GR, Fryxell GA (1977) The genus Thalassiosira: some species with a linear areola array. Beih. Nova Hedwigia 54:15-66. 
Hevia-Orube J, E Orive, H David, A Diez, A Laza-Martinez, I Miguel, S Seoane (2015) Molecular and morphological analyses of solitary forms of brackish Thalassiosiroid diatoms (Coscinodiscophyceae), with emphasis on their phenotypic plasticity. European Journal of Phycology 51(1).

Hoppenrath M, B Beszteri, G Drebes, H Halliger, JEE Van Beusekom, S Janisch, KH Wiltshire (2007) Thalassiosira species (Bacillariophyceae, Thalassiosirales) in the North Sea at Helgoland (German Bight) and Sylt (North Frisian Wadden Sea) - a first approach to assessing diversity. European Journal of Phycology 42 (3): $271-288$.

Hu S, Z Guo, T Li, EJ Carpenter, S Liu, S Lin (2014) Detecting in situ copepod diet diversity using molecular technique: development of a copepod/symbiotic ciliate-excluding eukaryote-inclusive PCR protocol. PLoS ONE 9(7): E103528.

Kaczmarska I, M Beaton, AC Benoit, LK Medlin (2006) Molecular phylogeny of selected members of the order Thalassiosirales (Bacillariophyta) and evolution of the fultoportula. J. Phycol. 42(1): 121-138.

Kaczmarska I, C Lovejoy, M Potvin, M Macgillivary (2009) Morphological and molecular characteristics of selected species of Minidiscus (bacillariophyta, Thalassiosiraceae) European Journal of Phycology 44: 461-475.

Karentz D, T Smayda (1984) Temperature and seasonal occurrence patterns of 30 dominant phytoplankton species in Narragansett Bay over a 22-year period (1959-1980). Mar Ecol Prog Ser 18: 277-293.

Krawczyk DW, A Witkowski, M Wroniecki, J Waniek, KJ Kurzydlowski, T Plocinski (2012) Reinterpretation of two diatom species from the West Greenland margin - Thalassiosira kushirensis and Thalassiosira antarctica var. borealis - hydrological consequences. Marine Micropaleontology 88-89: 1-14.

Larkin MA, G Blackshields, NP Borwn, R Chenna, PA McGettigan, H McWilliam, F Valentin, IM Wallace, A Wilm, R Lopez, JD Thompson, TJ Gibson, DG Higgins (2007) Clustal W and Clustal X version 2.0. Bioinformatics 23(21): 2947-2948.

Lawrence C and S Menden-Deuer (2012) Drivers of protistan grazing pressure: seasonal signals of plankton community composition and environmental conditions. Marine Ecology Progress Series 459: 39-52.

Legendre L (1990) The significance of microalgal blooms for fisheries and for the export of particulate organic carbon in oceans. Journal of Plankton Research 12 (4): 681-699. 
Li Y, TJ Smayda (1998) Temporal variability of chlorophyll in Narragansett Bay, 1973-1990. ICES Journal of Marine Science 55(4): 661-667.

Loman NJ, RV Misra, TJ Dallman, C Constantinidou, SE Gharbia, J Wain, MJ Pallen (2012) Performance comparison of benchtop high-throughput sequencing platforms. Nature Biotechnology 30: 434-439.

Luddington IA, I Kaczmarska, C Lovejoy (2012) Distance and Character-Based Evaluation of the V4 Region of the 18S rRNA Gene for the Identification of Diatoms (Bacillariophyceae). PLoS ONE 7(9): e45664. doi:10.1371/journal.pone.0045664

Treguer PJ, CL De La Rocha (2013) The World Ocean Silica Cycle. Annual Review of Marine Science 5: 477-501.

Mann DG, SJM Droop (1996) Biodiversity, biogeography and conservation of diatoms. Hydrobiologia 336: 19-32.

Mann DG (1999) The species concept in diatoms. Phycologia 38(6):437-495.

Mann DG, P Vanormelingen (2013) An inordinate fondness? The number, distributions and origins of diatom species. Journal of Eukaryotic Microbiology 60(4):414-20.

Marshall HG, RV Lacouture, C Buchanan, JM Johnson (2006) Estuarine, Coastal and Shelf Science 69(1-2): 10-18.

McQuoid MR, Hobson LA (1996) Diatom Resting Stages. Journal of Phycology 32: 889-902.

McQuoid MR, LA Hobson (1997) A 91-year record of seasonal and interannual variability of diatoms from laminated sediments in Saanich Inlet, British Columbia. Journal of Plankton Research 19(1): 173-194.

McQuoid MR, A Godhe (2004) Recruitment of coastal planktonic diatoms from benthic versus pelagic cells: Variations in bloom development and species composition. Limnology and Oceanography 49(4): 1123-1133.

Medlin LK, WHCF Kooistra, R Gersonde, U Wellbrock (1996) Evolution of the Diatoms (Bacillariophyta). II. Nuclear-Encoded Small-Subunit rRNA Sequence Comparisons Confirm a Paraphyletic Origin for the Centric Diatoms. Mol. Biol. Evol. 13(1):67-75.

Menden-Deuer S, EJ Lessard (2000) Carbon to volume relationships for dinoflagellates, diatoms and other protist plankton. Limnology and Oceanography 45(3): 569-579. 
Miklasz KA and MW Denny (2010) Diatom sinking speeds: Improved predictions and insight from modified Stokes' law. Limnology and Oceanography 55(6): 25132525. doi: 10.4319/1o.2010.55.6.2513

Muylaert K, K Sabbe (1996) The Diatom Genus Thalassiosira (Bacillariophyta) in the Estuaries of the Schelde (Belgium/The Netherlands) and the Elbe (Germany). Botanica Marina 36: 103-115.

Nixon SW, RW Fulweiler, BA Buckley, SL Granger, BL Nowicki, KM Henry (2009) The impact of changing climate on phenology, productivity, and benthicpelagic coupling in Narragansett Bay. Estuarine, Coastal and Shelf Science 82(1): 1-18.

Oviatt C, A Keller, L Reed (2002) Annual primary production in Narragansett Bay with no bay-wide winter-spring bloom. Estuarine, Coastal and Shelf Science 54: 1013-1026.

Pilson, MEQ (1985) Annual cycles of nutrients and chlorophyll in Narragansett Bay, Rhode Island. Journal of Marine Research 43: 849-873.

Popovich CA, AM Gayoso (1999) Effect of irradiance and temperature on the growth rate of Thalassiosira curveseriata Takano (Bacillariophyceae), a bloom diatom in Bahia Blanca estuary (Argentina). Journal of Plankton Research 21: 11011110.

Pratt DM (1965) The Winter-Spring Diatom Flowering in Narragansett Bay. Limnology and Oceanography 10(2): 173-184.

Quail MA, M Smith, P Coupland, TD Otto, SR Harris, TR Connor, A Bertoni, HP Swerdlow, Y Gu (2012) A tale of three next generation sequencing platforms: comparison of Ion Torrent, Pacific Biosciences and Illumina MiSeq sequencers. BMC Genomics 13:341. DOI: 10.1186/1471-2164-13-341.

Rodriguez-Ramos T, M Dornelas, E Maranon, P Cermeno (2013) Conventional sampling methods severely underestimate phytoplankton species richness. Journal of Plankton Research 36(2): 334-343.

Rousseaux CS, WW Gregg (2014) Interannual Variation in Phytoplankton Primary Production at a Global Scale. Remote Sensing 6: 1-19.

Rynearson TA, EO Line, EV Armbrust (2009) Metapopulation Structure in the Planktonic Diatom Ditylum brightwellii (Bacillariophyceae). Protist 160(1): $111-121$.

Sarno D, HC Wiebe, WHCF Kooistra, LK Medlin, I Percopo, A Zingone (2005) Diversity in the genus Skeletonema (bacillariophyceae). II. An assessment of 
the taxonomy of S. costatum-like species with the description of four new species. J. Phycol. 41(1): 151-176.

Sarthou G, KR Timmermans, S Blain, P Treguer (2004) Growth physiology and fate of diatoms in the ocean: a review. Journal of Sea Research 53(1-2):25-42. doi: 10.1016/j.seares.200.01.007

Smayda TJ (1969) The suspension and sinking of phytoplankton in the sea. Oceanography and marine biology 8.

Smayda TJ (1998) Patterns of variability characterizing marine phytoplankton, with examples from Narragansett Bay. ICES Journal of Marine Science 55: 562573.

Smith LM, S Whitehouse, CA Oviatt (2010) Impacts of Climate Change on Narragansett Bay. Northeastern Naturalist 17(1): 77-90.

Strathmann RR (1967) Estimating the organic carbon content of phytoplankton from cell volume or plasma volume. Limnology and Oceanography 12: 411-418.

Sullivan BK, D Van Keuren, M Clancy (2001) Timing and size of blooms of the ctenophore Mnemiopsis leidyi in relation to temperature in Narragansett Bay, RI. Hydrobiologia 451: 113-120.

Sun J, Y Feng, Y Zhang, DA Hutchins (2007) Fast microzooplankton grazing on fastgrowing, low-biomass phytoplankton: a case study in spring in Chesapeake Bay, Delaware Inland Bays and Delaware Bay. Hydrobiologia 589: 127-139.

Sunda WG, SA Huntsman (1995) Iron uptake and growth limitation in oceanic and coastal phytoplankton. Marine Chemistry 50: 189-206.

Swofford, D. L. 2003. PAUP*. Phylogenetic Analysis Using Parsimony (*and Other Methods). Version 4. Sinauer Associates, Sunderland, Massachusetts.

Tomas CR ed. (1997) Identifying marine phytoplankton. Academic press.

Trigueros JM, E Orive (2001) Seasonal variations of diatoms and dinoflagellates in a shallow, temperate estuary, with emphasis on neritic assemblages. Hydrobiologia 444(1-3): 119-133.

Veldhuis MJW, GW Kraay, KR Timmermans (2001) Cell death in phytoplankton: correlation between changes in membrane permeability, photosynthetic activity, pigmentation and growth. European Journal of Phycology 36: 167177.

White TJ, TD Bruns, SB Lee, JW Taylor (1990) Amplification and Direct Sequencing of Fungal Ribosomal RNA Genes for Phylogenetics. In Innis MA, Gelfand 
DH, Sninsky JJ, White TJ (eds) PCR Protocols: a Guide to Methods and Applications. Academic Press, London, pp315-322.

Whittaker KA, DR Rignanese, RJ Olson, TA Rynearson (2012) Molecular subdivision of the marine diatom Thalassiosira rotula in relation to geographic distribution, genome size, and physiology. BMC Evol. Biol. 12(1): 209.

Windecker, LA (2010) Ten years of phytoplankton species abundance patterns in midNarragansett Bay, Rhode Island: 1999-2008. Graduate School of Oceanography, University of Rhode Island. M.S. Thesis.

Yoshie N, K Suzuki, A Kuwata, J Nishioka, H Saito (2010) Temporal and spatial variations in photosynthetic physiology of diatoms during the spring bloom in the western subarctic Pacific. Marine Ecology Progress Series 399: 39-52.

Zimmermann J, R Jahn, B Gemeinholzer (2011) Barcoding diatoms: evaluation of the V4 subregion on the 18S rRNA gene including new primers and protocols. Organisms Diversity and Evolution 11(3): 173-192.

Zhu F, R Massana, F Not, D Marie, D Vaulot (2005) Mapping of picoeukaryotes in marine ecosystems with quantitative PCR of the 18S rRNA gene. FEMS Microbiology Ecology 52: 79-92. doi:10.1016/j.femsec.2004.10.006 